\title{
Free to Choose? \\ Reform, Choice, and Consideration Sets in the English National Health Service
}

\author{
By Martin Gaynor and Carol Propper and Stephan Seiler*
}

\begin{abstract}
Choice in public services is controversial. We exploit a reform in the English National Health Service to assess the effect of removing constraints on patient choice. We estimate a demand model that explicitly captures the removal of the choice constraints imposed on patients. We find that, post-removal, patients became more responsive to clinical quality. This led to a modest reduction in mortality and a substantial increase in patient welfare. The elasticity of demand faced by hospitals increased substantially post-reform and we find evidence that hospitals responded to the enhanced incentives by improving quality. This suggests greater choice can raise quality. JEL: D12, I11, I18, L13, L30

Keywords: Demand Estimation, Non-price Competition, Health Economics, Patient Choice, Health Care Reform
\end{abstract}

Governments facing fiscal pressure have increasingly turned to proposals to create or enhance consumer choice for public services (see, e.g., Besley and Ghatak 2003, Blöchliger 2008, Hoxby 2003, Le Grand 2003). In health care, choice is a popular reform model adopted by administrations of different political orientations in many countries, including the US, the UK, Denmark, Italy (Lombardy), the Netherlands, Germany and Sweden. The belief is that by increasing choice for patients, providers of care or insurers will become more responsive to patient demand, which in turn will drive greater efficiency in the delivery and funding of health care. However, whether enhanced patient choice will make hospital choice more responsive to quality is not well established, although the consequences of poor quality in health care can be dire. Patients' health can be severely compromised by poor quality care, including, as we show below, an increased risk of death. Thus there is a need to understand the responses of health care consumers

* Gaynor: Heinz College, Carnegie Mellon University, 5000 Forbes Ave., Pittsburgh, PA 15213-3890, USA, University of Bristol, and NBER, mgaynor@cmu.edu. Propper: Business School, Imperial College London, Tanaka Building, South Kensington Campus, London SW7 2AZ, UK, University of Bristol, and CEPR, C.Propper@imperial.ac.uk. Seiler: Graduate School of Business, Stanford University, 655 Knight Way, Stanford, CA 94305, USA, sseiler@stanford.edu. We are grateful to the Editor, Penny Goldberg, and three anonymous referees, whose comments substantially improved the paper. Helpful comments were provided by Alon Eizenberg, Kate Ho, Adam Rosen, Michelle Sovinsky, John Van Reenen, and participants at seminars at a number of universities and conferences. We are grateful for financial support to Propper from the ESRC under grant ES/J023108/1 and to the Department of Health under the HREP programme. Any errors and all opinions are the responsibility of the authors alone. The authors declare that they have no relevant or material financial interests that relate to the research described in this paper. 
when they are offered more choice. This is exactly the issue we address here.

To do this we exploit a reform which introduced patient choice and tie this to the estimation of a structural demand model that explicitly incorporates the institutional features of the reform. This enables us to identify the effect of increasing choice on patient behavior. We use the model to quantify the gains from the reform in terms of patient welfare and survival and to analyze how the changes in patients' choices translate into changes in the competitive environment faced by hospitals.

The reform we exploit is from the English National Health Service (NHS). In 2006, the UK government mandated that patients in the English NHS had to be offered a choice of 5 hospitals when referred by their physician to a hospital for treatment. Prior to this reform, there was no requirement that patients be offered choice. The reform provides exogenous variation in the ability to exercise choice over time and, as the choice set of hospitals is (almost) constant around the introduction of the choice reform, allows us to cleanly identify the effect of greater choice while holding the underlying market structure fixed. We use this reform to estimate a structural model of demand under both pre-reform constrained choice and post-reform liberated choice.

In the post-reform period we assume that, as patients were mandated free choice, the choices made by the referring physician fully reflect patient preferences over hospital characteristics (quality of care, waiting time, travel distance). Prereform, patient choice was constrained. We do not observe the choice sets available to patients. Therefore, to model hospital choice pre-reform we adopt an approach which draws from the consideration set literature (see, e.g., Goeree 2008, Mehta, Rajiv and Srinivasan 2003). We model the patient's choice set as containing a subset of the full set of available options. This subset is determined by the physician's preferences, which were shaped by the institutional structure of the pre-reform referral system. Specifically, in the pre-reform period referrals were paid for by a selective contracting system that covered referrals to only a subset of all potential hospitals. This system, discussed in detail in Section I.B below, made it easier for a physician to refer patients to hospitals located within local administrative boundaries. Exploiting these institutional features, we estimate the extent to which the referring physician cares about patient welfare by allowing him to offer a (potentially limited) set of hospitals from which the patient chooses the one with the highest utility according to her preferences. ${ }^{1}$ This allows us to identify the extent to which patients were constrained pre-reform. To estimate the model we take the case of coronary artery bypass graft (CABG) surgery. This is well suited to our purpose as most CABGs are elective and scheduled well in advance, giving patients an opportunity to exercise choice if allowed to do so. ${ }^{2}$

\footnotetext{
${ }^{1}$ The model nests the extreme cases of unconstrained and fully constrained choice, where in the latter case the physician offers only a singleton choice set, his preferred hospital, to the patient.

${ }^{2} \mathrm{~A}$ relatively small proportion of CABG surgeries are performed on an emergency basis. We exclude
} 
We begin by providing descriptive evidence to show that, while on average distance travelled changed little post-reform, there is clear evidence of improved sorting of patients to higher quality hospitals after the reform. Furthermore, we see these patterns only for elective cases but not for emergencies, suggesting that choice is the key driver. We then estimate the structural model and use the estimates to quantify the impact of the reform. First, we analyze the direct impact of the removal of constraints on the ability of patients to choose a hospital according to their preferences. This leads to a reallocation of patients to higher quality hospitals and thus an improvement in patient welfare and expected survival. We find a modest decrease in patient mortality of around 3.5 more patients per year (approximately a 3 percent decrease) had patients had free choice in the pre-reform period. The utility increase for the average patient as a result of the reform is equivalent to that from about a 50 percent reduction in the travel distance to a hospital. This is relatively large: since prices in the NHS are zero, distance and waiting time are the main costs of getting treatment. We also find that the quality elasticity of demand increased for all types of patients. The demand elasticity increased relatively more for sicker and lower income patients. The latter effect is particularly interesting because there have been concerns expressed about the impacts of pro-choice policies on the poor (see, e.g., Cookson, Laudicella and Donni 2013). We do not find these to be substantiated here.

Second, we analyze the change in the competitive environment in the hospital market. To quantify the effect on competition, we aggregate the patient-level elasticities to the hospital level and find that the competitive environment changed substantially. For the average hospital an increase in mortality leads to a fivetimes larger drop in market share post-reform relative to pre-reform. This lends support to the notion that hospitals had stronger incentives to improve quality due to the introduction of patient choice. Finally, we analyze the supply-side response to the reform and find that hospitals which experienced the largest increase in elasticity also had the biggest reduction in their mortality rates.

Our paper makes a contribution to two distinct literatures. The first is the impact of pro-competitive and choice based reforms on the quality of health care provision. Kessler and McClellan (2000) provided initial evidence on the effect of competition on quality in the US Medicare program. The literature on health care competition and quality in the US has grown greatly since then. The overwhelming majority of these papers take non-structural approaches. Gaynor and Town (2012) and Gaynor, Ho and Town (2015) survey those papers and their results. Most (but not all) papers find that competition leads to enhanced quality. In the UK context, the primary analyses of the impact of the 2006 reforms on patient outcomes are Gaynor, Moreno-Serra and Propper (2013) and Cooper et al. (2011). They estimate reduced form models of changes in hospital mortality

those from our main analysis and use them as a placebo test for the robustness of our results. We provide factual details on CABGs in Section I.A. 
outcomes regressed on measures of market concentration. Both papers find that patient outcomes at the hospital level improved and conclude that competition and choice improved quality.

Our paper advances the prior literature by explicitly modeling the choice process before and after the reform, allowing us to estimate the extent of constraints pre-reform. The nature of our structural model allows us to carefully decompose the effect of the reform along various dimensions. As mentioned above, we first quantify the changes in patient mortality and utility from the reallocation of patients to better hospitals following the liberation of choice. Second, we assess the effect on supply-side incentives. We compute the change in hospital elasticities with respect to quality after the reform and assess whether hospitals reacted to the change in the competitive environment by improving their quality (by lowering mortality rates). The small number of earlier papers primarily focuses on just the last part of this assessment: hospitals' reactions to the reform in terms of quality improvements. We provide a much more comprehensive picture of the impact of increasing choice. Furthermore, while there is a large literature estimating demand models in health care, either directly or as part of a larger model (e.g., of hospital competition), these papers are not typically able to separately identify patient versus physician preferences due to a lack of sources of identifying variation..$^{3,4}$ The setting we study provides us with a unique opportunity to identify patient preferences separately from physician preferences because of the change in the choice process due to the removal of constraints.

Secondly, our paper contributes to the literature on consideration set formation, for example Roberts and Lattin (1991), Andrews and Srinivasan (1995), Bronnenberg and Vanhonacker (1996), Mehta, Rajiv and Srinivasan (2003), Goeree (2008), and Seiler (2013). We add to this literature by exploiting a unique aspect of our data: the fact that we observe a change in the process by which consideration sets are formed. In particular, observing unconstrained choice post-reform allows us to estimate preferences in a setting where constraints had no impact on choice. Given those preference estimates, we then use choices in the pre-reform period to estimate the process driving the consideration set formation. Within the health care literature, Ho (2006) and Dafny, Ho and Varela (2013) also analyze the effect of removing choice constraints. However, in their settings the constrained choice sets are observed in the data and the papers evaluate the welfare effect of their removal in a counterfactual. We observe a change in the way consideration sets are formed due to the reform, but as the precise choice sets being offered are not observed we have to infer the constraining process from the

\footnotetext{
${ }^{3}$ Luft et al. (1990), Tay (2003), and Howard (2005) are examples of demand estimation for the US. Sivey (2008), Beckert, Christensen and Collyer (2012), Varkevisser, van der Geest and Schut (2012), and Moscone, Tosetti and Vittadini (2012) are examples for Europe. Capps, Dranove and Satterthwaite (2003), Gaynor and Vogt (2003), and Gowrisankaran, Nevo and Town (2015) are examples of choice estimation within the context of models of hospital competition.

${ }^{4}$ Beckert (2015) proposes a methodological approach to identifying patient vs physician preferences.
} 
choice data.

The paper is structured as follows. Section I describes the institutional setting. Section II outlines the modeling framework. Section III describes the data and Section IV presents econometric issues and estimation methods. Section V presents reduced-form results followed by Section VI, which presents the results from the structural estimation. Section VII quantifies the impact of the reform along various dimensions using our model estimates. The final section contains concluding remarks.

\section{Institutional Details}

\section{A. CABG: Medical Background}

A coronary artery bypass graft $(\mathrm{CABG})$ is a surgical procedure widely used to treat coronary heart disease. It is used for people with severe angina (chest pain due to coronary heart disease) or who are at high risk of a heart attack. It diverts blood around narrowed or clogged parts of the major arteries to improve blood flow and oxygen supply to the heart. It involves taking a blood vessel from another part of the body, usually the chest or leg, and attaching it to the coronary artery above and below the narrowed area or blockage. This new blood vessel, known as a graft, diverts the flow of blood around the part of the coronary artery that is narrowed or blocked. ${ }^{5}$ Successful bypass surgery improves symptoms and lowers the risk of heart attack.

We focus on CABG for three reasons. First, it is a commonly performed procedure. About 13,500 patients per year receive elective CABGs in England, making CABG one of the most frequently performed elective treatments. ${ }^{6}$ The fact that it is commonly performed provides us with statistical power and means that CABG is quantitatively important. Second, CABG is mostly performed on an elective, as opposed to an emergency, basis. Therefore, patients can exercise choice among alternatives, which is not usually the case for emergency treatments. Third, patients who receive heart bypass surgery are very sick, so CABG is among the most risky elective treatments and mortality is a fairly common outcome. ${ }^{7}$ The relatively high frequency of death means mortality is a reliable and easily observed measure of quality. Other dimensions of quality which characterize other medical procedures are harder to observe and may be less reliably recorded.

Patients in the NHS who present with symptoms of coronary artery disease or

\footnotetext{
${ }^{5}$ http://www.nhs.uk/Conditions/Coronary-artery-bypass/Pages/Introduction. aspx

${ }^{6}$ In the US the number is 415,000 , making CABG one of the top 10 most common non-obstetric surgical procedures (National Hospital Discharge Survey 2010, http://www.cdc.gov/nchs/nhds/nhds_ products.htm).

${ }^{7}$ Other procedures commonly used in the health economics literature, such as AMI (acute myocardial infarction) treatment have higher mortality rates, but are primarily emergency treatments. They are therefore not directly relevant for an analysis of patient choice.
} 
angina are referred to a cardiologist in a hospital who conducts tests and may then perform a non-surgical procedure to unblock the artery (called angioplasty or percutaneous coronary intervention, PCI). If this fails, the patient will then be referred for a CABG to be performed by a cardiac surgeon and put on an elective waiting list for this treatment. Cardiologists operate in almost all short term general NHS hospitals but CABGs are performed only at a limited number of hospitals. The referral is typically made by the cardiologist but in some cases may be made by the patient's primary care physician (the General Practitioner). ${ }^{8}$

\section{B. The Choice Reform}

In the UK health care is tax financed and free at the point of use. Almost all care is provided by the National Health Service (NHS). Primary care is provided in the community by publicly funded physicians known as General Practitioners (GPs). GPs are self employed and work in practices which on average contain 4 to 5 GPs. They earn their income by providing services to the NHS. Patients have a very limited choice of GP. ${ }^{9}$ GPs also act as gatekeepers for hospital-based (known as secondary) care, sending patients who need treatment to a specific hospital. Secondary care (including cardiology and cardiac surgery) is provided in publicly funded (NHS) hospitals. NHS hospitals are free-standing public organizations known as NHS Trusts. In these hospitals, the physicians are salaried employees and are generally employed only in one NHS Trust. Publicly funded bodies covering specific geographic areas, called Primary Care Trusts (PCTs), have the task of buying hospital-based health care for their population on behalf of the GP practices in their area. In the period we examine, PCTs also oversaw the GP practices in their area, monitoring their prescribing, inspecting their premises, providing financial assistance for practice computing, financing community nurses to complement GP services and providing information to practices to allow them to compare their performance with other practices in the PCT. On average each PCT had around 20 or so GP practices in their area (Santos, Gravelle and Propper 2015).

In the pre-reform period, when purchasing hospital based care, buyers (PCTs) and sellers (the NHS Trusts) negotiated over price, service quality (mainly waiting times rather than clinical outcomes) and volume on an annual basis. The majority of contracts were annual bulk-purchasing contracts between the buyers and a limited number of sellers. Patients requiring secondary care were generally referred by their GPs to the local hospital that provided the service they required and were not offered choice over which hospital they went to. Instead the hospital to which a patient was sent was determined by the selective contracts negotiated by the PCTs on behalf of all the GPs in their area and covering all the patients

\footnotetext{
${ }^{8}$ Payment for the treatment is discussed in the next section.

${ }^{9}$ Patients almost always have to choose a GP located near to where they live. There are currently (as of 2016) proposals to increase choice.
} 
registered with these GPs. ${ }^{10}$ PCTs had to make additional, separate, payments for any referrals physicians made to non-contracted hospitals. Thus GPs whose patients were referred off-contract were likely to be subject to scrutiny by, and discussions with, the PCT about their behavior. In the choice of hospitals with which to contract, PCTs had a strong tendency to support local providers, i.e., ones that fell within their geographical boundaries. This was for both historic reasons (PCTs and hospitals had, pre-1991, been joint administrative entities) and to assure local supply of care. So for these contractual reasons physicians were more likely to refer patients to the nearby hospital(s) with which their PCT had negotiated a contract.

From late 2002 the government started to develop the components of a reform package intended to bring about hospital competition from 2006 onwards. ${ }^{11}$ There were several elements to this policy. First, under law, after January 2006 patients had to be offered a choice of five providers for where they had their hospital care (Farrar et al. 2007). GPs were required (and provided with software) to ensure that patients were made aware of, and offered, choice.

Second, the government introduced a new information system that enabled paperless referrals and appointment bookings and provided information on the different dimensions of service (waiting times and some measures of clinical quality) to help patients make more informed choices. This system, known as "Choose and Book," allows patients to book hospital appointments online, with their GP, or by telephone. The booking interface gave the person booking the appointment the ability to search for hospitals based on geographic distance and to see estimates of each hospital's waiting time. From 2007 the government also introduced a website designed to provide further information to help patients' choices. This included information collected by the national hospital accreditation bodies, such as risk-adjusted mortality rates and detailed information on waiting times, infection rates and hospital activity rates for particular procedures, as well as information on hospital accessibility, general visiting hours and parking arrangements (http://www. chooseandbook.nhs.uk/).

Third, from 2006 onwards the NHS adopted a payment system in which hospitals were paid fixed, regulated, prices for treating patients (a regulated price system similar to the Medicare hospital payment system in the US). This fixed price system covered around $70 \%$ of hospital services, including CABG. This change in the remuneration system meant that GPs (and hospital specialists making referrals for treatment to a hospital other than their own) were no longer restricted in these referral decisions by their PCT's contractual arrangements with individual hospitals. $^{12}$

\footnotetext{
${ }^{10}$ Almost all patients in the PCT will be registered with a GP in the PCT.

${ }^{11}$ A previous hospital competition policy had operated 1991-1997 but was dropped when the Labour government came to power in 1997 (Propper 2012).

${ }^{12}$ The reforms also promoted the use of (mainly) new private providers of care. However, use of these
} 
In the particular case of $\mathrm{CABG}$, which is a specialized treatment provided at only a few hospitals, the Choose and Book information system was probably less important than for more routine treatments. What was more important was the removal of selective contracting and the right to choose. These allowed the patient to choose, with the aid of their GP, the initial hospital in which to see a cardiologist, and gave the cardiologist freedom in where they sent patients for a CABG. In these choices the patient, and the physicians involved, were no longer restricted in their decisions by selective contracting.

It is important to note that the reforms did not change financial incentives for the patient or financial payments to referring physicians. Patients did not pay for medical care either before or after the reforms. Neither GPs nor hospital based specialists (including cardiologists) received payments that were linked to their referral advice to the patient, either before or after the reform. However, the reform did have a financial impact on PCTs, which were overseeing GPs, and pre-reform had an interest in referring patients to hospitals that were covered by contractual arrangements. Therefore, by ending selective contracting, what the reforms did was to remove legal and (indirect) financial restrictions on both physicians and patients which enabled referral decisions to be more flexible and tailored to individual patients.

It is possible that patient preferences influenced referral decisions even before the formal introduction of patient choice. For instance, a well-informed patient with a strong preference might have been able to convince the physician to refer her to a specific hospital. The effect of the reforms was to make such choice available and far more explicit for all patients. Similarly, physician agency might have led to referrals pre-reform which were in line with patient preferences although not directly selected by the patient. However, the nature of selective contracting suggests that physician incentives were not fully aligned with patients' interests. In particular, contractual arrangements made by PCTs with nearby hospitals made referrals outside that set of hospitals substantially more difficult pre-reform. Rather than assuming that patients were constrained pre-reform, we let the data tell us the extent to which patient preferences influenced choice in the pre-reform period. In the econometric model we explicitly estimate the degree to which patient preferences were constrained before the reform, thus allowing for less than fully constrained choices.

\section{Modeling Approach}

Our framework for analyzing the impact of the reforms on hospital demand is comprised of two components: (1) a model of patient choice under the post-

was very limited and accounted for less than $1 \%$ of all NHS care during the period in which we analyze. The main services purchased in the private sector were simple elective services (primarily hip and knee replacements and cataract removal) rather than complex interventions such as CABG or cardiac care more generally. 
reform regime where choice was liberated and (2) a representation of the process by which choice was constrained before the reform.

\section{A. Patient Preferences}

In the post-reform period, when choice is liberated, we assume that referrals reflect choice from the full set of hospitals that perform CABG surgery based on patients' utility from this choice. ${ }^{13}$ We note that in the case of a complex procedure such as CABG, patients will typically seek and follow advice from their referring physician. We make the key assumption that after the reform, the physician acts as a perfect agent for his patient by providing her with information and advice based on his best understanding of the patient's preferences. We make this assumption based on the institutional features described above. Specifically, neither the GP nor the cardiologist have any incentive post-reform not to act in the patient's best interest. They do not receive payments linked to where they refer and they are no longer bound by selective contracting. Furthermore, physicians were mandated to explicitly involve patients in the decision-making process by offering them choice from a set of hospitals. Both of these aspects of the reform together are the reason for assuming that post-reform referrals are based solely on patient preferences.

Price in the NHS is zero for the consumer, so utility is only a function of patient and hospital characteristics. The key factors which affect hospital choice are the quality of care, the amount of time a patient has to wait for surgery, and distance from the hospital. We also allow for preference heterogeneity across different patient characteristics. Finally, we assume that all people who require a CABG are sick enough that they get one (after a wait). As a consequence, there is no outside good. ${ }^{14}$

Let a patient $i$ obtain the following utility from choosing hospital $j$ :

$$
U_{i j}=\beta_{w i} W_{j t}+\beta_{z i} Z_{j t}+f\left(D_{i j}\right)+\xi_{j}+\varepsilon_{i j}
$$

where $W_{j t}$ denotes the average waiting time for a CABG at hospital $j$ in time period $t, Z_{j t}$ denotes the quality of clinical care at the hospital in that time period,

\footnotetext{
${ }^{13}$ There are only 29 (both pre- and post-reform) hospitals in England which offer CABGs and all treat a fairly large number of cases on a regular basis. We confirmed, from independent sources, that we cover the exhaustive set of possible CABG providers. So it is not the case that some options are excluded from the analysis because they were never chosen during the sample period. Further, while physicians were only required to offer patients the choice of 5 hospitals post-reform, they were able to refer to any hospital that performs CABGs. A non-negligible fraction of patients receive treatment at a hospital other than one of the 5 closest hospitals. We therefore assume in estimation that all 29 hospitals are available to all patients.

${ }^{14}$ This assumption is common in the healthcare literature. Capps, Dranove and Satterthwaite (2003) and Ho (2006) (among others) make the same assumption when estimating demand models for hospital choice.
} 
and $D_{i j}$ is the distance from patient $i$ 's location to the location of hospital $j .{ }^{15}$ The function $f\left(D_{i j}\right)$ is a transformation of $D_{i j}$ that reflects the (non-linear) preference for distance to the hospital. $\xi_{j}$ denotes unobserved hospital quality and $\varepsilon_{i j}$ is an idiosyncratic taste shock that is iid extreme value. We incorporate preference heterogeneity by allowing the coefficients on waiting times and mortality $\left(\beta_{w i}\right.$ and $\beta_{z i}$ ) to vary with patient characteristics.

\section{B. Constraints on Patient Choice}

To model the fact that choice before the reform was limited, we assume that pre-reform, physicians offered their patients a limited set of options. This referral behavior was determined by their own utility, which we model based on the institutional features of the pre-reform contractual arrangement and referral process described in Section I.B. As explained, for contractual reasons physicians were more likely to refer patients to the nearby hospital(s) with which their PCT had negotiated a contract and discouraged from referring elsewhere. In addition, physicians were likely to have preferences for referrals to certain hospitals based on past interactions with the hospital or particular surgeons at the hospital. We capture these referral incentives by making physician utility a function of hospital fixed effects and distance related variables as well as an indicator for whether the hospital was located in the PCT of the referring GP.

More formally, we define the utility the physician receives from referring patient $i$ to hospital $j$ as

$$
V_{i j}=g\left(D_{i j}\right)+\zeta_{j}+\nu_{i j}
$$

where $g\left(D_{i j}\right)$ is a transformation of $D_{i j}$ that reflects the (non-linear) preference for distance to the hospital which facilitates referrals. ${ }^{16} \zeta_{j}$ denotes unobserved (to the econometrician) physicians' assessment of hospital quality and $\nu_{i j}$ is an idiosyncratic shock that is iid extreme value. Note that, for simplicity of exposition, we index the physician's utility by the index $i$ of the patient he is referring. This has a close mapping to our data: the physician's influence via offering a limited set of hospitals constitutes a latent process and is not directly observable. In the data we only see the referral outcome for patient $i$. We maintain this notation for the remainder of the paper.

Details of the specific variables included in physician and patient utility are pro-

\footnotetext{
${ }^{15}$ Note that strictly speaking utility has a $t$ subscript because hospital characteristics vary over time. However, we observe each patient only once and every patient $i$ has a unique time-period $t$ associated with his referral. We therefore denote the utility function above as patient/hospital but not time-periodspecific $\left(U_{i j}\right)$.

${ }^{16}$ The indicator for whether the hospital is located in the PCT of the referring GP is included in $g\left(D_{i j}\right)$.
} 
vided in the estimation section (Section IV). In brief, to implement the approach discussed here, we include only aspects of the hospital that the physician directly cares about in the physician's utility function. The preferences physicians are likely to have for referrals to certain hospitals based on contractual relationships or past interactions are captured through the set of hospital fixed effects $\left(\zeta_{j}\right)$ as well as a dummy for whether the hospital is located in the physician's PCT. Importantly, waiting times and quality are not included in physician utility, as we think of those variables as influencing the physician's decision only indirectly via their influence on patient utility.

Contrary to a standard choice model, we assume that the physician is not ultimately making the decision of which hospital to visit, but offers a set of options from which the patient chooses the highest utility one according to his preferences. More specifically, we assume that the physician includes hospital $k$ in the consideration set, that is the (potentially limited) set of hospitals patients can choose from, if

$$
V_{i k} \geq \max _{j \in J}\left(V_{i j}\right)-\lambda_{i}
$$

where $\lambda_{i} \geq 0$ and $J$ denotes the full set of hospitals. In other words, every hospital that is within a distance of $\lambda_{i}$ (in utility space) relative to the highest utility option is included in the consideration set. The highest utility hospital is always included, and the number of options included in the set increases the higher is the value of $\lambda_{i}$.

The particular value of the constraining parameter $\lambda_{i}$ captures the extent to which the physician cares about patient utility and allows the patient's preferences to influence choice. In the case of $\lambda_{i}=0$, the physician picks the highest utility option according to his preferences and the patient's preferences have no bearing on the choice. In this case, the consideration set formation process collapses to a discrete choice model based on physician preferences. For $\lambda_{i}>0$ the physician might include multiple hospitals in the choice set. Whether and how many are included depends on the specific value of $\lambda_{i}$ as well as how similar the utilities of all hospitals are to each other. $\lambda_{i}$ is a parameter to be estimated and the main driver of consideration set size. In order to allow for the reform to differentially affect different groups of patients we allow $\lambda_{i}$ to vary across patient characteristics.

A few comments on this way of modeling the consideration set process are in order. We believe that our approach reflects actual decision-making well and at the same time is parsimonious, in the sense that we are able to model the degree to which patient preferences are constrained through one parameter: $\lambda$. Our framework is different from other approaches in the literature due largely to the nature of the forces constraining patient choice. In the consideration set literature 
in consumer goods markets the limited nature of choice sets usually originates from limited information acquisition. ${ }^{17}$ Instead, in our case, the constraining force is the joint-decision making process, which involves the patient and physician and in which the physician had a dominant role before the liberation of choice. ${ }^{18}$

The paper closest to ours is Goeree (2008), who models the effect of advertising on consumer's consideration sets. However, our modeling approach is different in a few key aspects. In contrast to our paper, Goeree (2008) models the probability of inclusion into the choice set separately for each product. This implies that the inclusion probabilities are independent across products. This is not the case in our setting, where a change in physician utility for one hospital can influence the inclusion probabilities of other hospitals. A second difference is that her setup allows for a strictly positive probability of an empty consideration set, which is not permitted in our model (patients have to be offered the choice of at least one hospital). Both features are appropriate in the context of advertising and personal computer purchases, but less attractive for our setting. First, our model assures that a patient needing a CABG will be offered the choice of at least one hospital. Second, it seems reasonable that the characteristics of all available hospitals shape the consideration set size and composition. In our model, the presence of a particularly attractive option can lead to a smaller choice set by "pushing" other hospitals out of the consideration set. For instance, a hospital at 10 kilometers distance is less likely to be included if another hospital exists that is located at a distance of only 5 kilometers. ${ }^{19}$

Finally, an alternative modeling approach we could take would be to have expected patient utility directly enter the physician's utility function. However, expected patient utility is defined over all possible consideration set permutations, of which there are $2^{29}-1(=536,870,911)$ for 29 available options. This approach would therefore require us to write down physician utility over all the possible one billion compositions of the consideration set. Instead, our framework allows us to compute utility for each option separately and then derive the consideration set based on this set of utilities and the value of $\lambda$. This approach considerably decreases the computational burden and thereby makes the estimation of the model feasible.

\footnotetext{
${ }^{17}$ Mehta, Rajiv and Srinivasan (2003), Kim, Albuquerque and Bronnenberg (2010) and Honka (2014) model the consumer's decision to gather information in a model of consumer search. Our case is less comparable with models of consumer search and has more in common with the case of external information provision, such as in Goeree (2008), in the sense that patients do not actively influence the formation of consideration sets.

${ }^{18}$ For other papers which allow for an agent to be involved in the choice process see Baker, Bundorf and Kessler (2015) for an empirical examination and Beckert (2015) for an econometric model.

${ }^{19}$ More generally, increasing the utility of the highest utility hospital (holding everything else constant) will increase the maximum utility level. As a consequence fewer hospitals will tend to be within $\lambda$ distance in utility-space from the highest utility hospital. This mechanism will lead to a smaller consideration set.
} 


\section{Data and Descriptive Statistics}

We use data from the UK Department of Health's Hospital Episode Statistics (HES) dataset, which is an administrative dataset containing information on every English NHS hospital inpatient admission. The data contain details of the medical procedures which the patient received (classified according to OPCS $\operatorname{codes}^{20}$ ) and up to 14 diagnoses, classified according to the ICD-10 classification. ${ }^{21}$ We have data on the universe of inpatient discharges receiving CABG surgery from every hospital in the NHS in England from April 2003 to March 2008, corresponding to the UK financial years 2003 to 2007 . About $25 \%$ of all CABGs are performed as part of an emergency treatment and are excluded from the main analysis. This gives us approximately 13,500 elective CABG discharges performed at 29 hospitals per year. We define January 2004 until March 2005 as the pre-reform time period and January 2007 to March 2008 as the post-reform time period due to the fact that the reform was phased in gradually over 2005 and 2006 . We provide more detail on the specific timing of the introduction of the reform in online Appendix A.

HES contains information on the postal code of the neighborhood in which the patient lives and patient characteristics such as age, sex, and co-morbidities. ${ }^{22}$ At the patient-level we observe the time elapsed between the referral and the actual treatment, i.e. the patient's waiting time. We also observe whether the patient died (in the hospital) within 30 days of the treatment. We can therefore compute hospital level CABG-specific waiting times and mortality rates by aggregating the data at the hospital level over the relevant time period. Finally, from the hospital location and the patient's postcode, we compute the distance to the hospital. A list of sources for the data is in online Appendix E.

\section{A. Measuring Clinical Quality of Care}

We need to define an appropriate measure for the quality of clinical service. Due to the relatively high risk of death following a CABG procedure, we assume the survival probability at a specific hospital is the primary quality metric patients care about. We thus use mortality rates as a quality measure.

One might be concerned that mortality rates do not correctly reflect differences in survival probabilities due to differences in case-mix across hospitals. We therefore implement an empirical test to assess the role of case-mix differences across hospitals, which we describe in detail in online Appendix B. In summary,

\footnotetext{
${ }^{20}$ OPCS is a procedural classification for the coding of operations, procedures and interventions performed in the NHS. It is comparable to the CPT codes used for procedural classification in the US.

${ }^{21}$ These are the 10th version of the International Classification of Disease (ICD) codes and are the standard codes used internationally for diagnoses.

${ }^{22}$ Co-morbidities are additional diagnoses associated with greater sickness, for example, a CABG patient who is also a diabetic.
} 
we regress mortality (at the individual level) on a set of hospital dummies which we instrument with distance to each hospital, following similar approaches by Gowrisankaran and Town (1999) and Geweke, Gowrisankaran and Town (2003). ${ }^{23}$ Importantly, this IV estimation approach allows us to test whether case-mix varies significantly across hospitals by comparing the coefficients on the hospital dummies from an OLS regression (which are equal to the unadjusted mortality rate) with the estimates from the IV regression via a Hausman test. ${ }^{24}$ Doing so, we find that we cannot reject the null hypothesis that the OLS and IV estimates are the same. We hence conclude that case-mix differences across hospitals are small enough not to affect the mortality rates significantly and therefore use the unadjusted mortality rate as a measure of the clinical quality of the hospital. This is simpler and avoids introducing another source of error into the estimation from case-mix adjustment. ${ }^{25}$

\section{B. Hospital Characteristics}

In contrast to many other procedures, CABGs are only offered by a small set of hospitals. Of around 170 short term general (acute) public hospitals within the NHS, only 29 hospitals offer bypass operations. There was almost no change in market structure around the time of the policy reform. ${ }^{26}$ The choice set faced by patients is nearly identical before and after the reform, which allows us to separate the impact of greater choice from a possible change in market structure. ${ }^{27}$ Figure 1 provides a map of the locations of NHS CABG-performing hospitals. Also, while in principle patients could choose privately funded treatment, in practice they did not. ${ }^{28}$

\footnotetext{
${ }^{23}$ This assumes that people do not choose where they live relative to CABG hospitals based on their unobservable health status. This assumption is universally employed in estimating models of hospital choice, e.g., Kessler and McClellan (2000), Gowrisankaran and Town (1999), Capps, Dranove and Satterthwaite (2003), Gaynor and Vogt (2003), Ho (2009), Beckert, Christensen and Collyer (2012). We provide additional evidence for this assumption in the online Appendix.

${ }^{24} \mathrm{We}$ assess the strength of the instruments via F-tests for each of the 284 first stage regressions (one for each hospital/quarter pair). The instruments are strong: the mean of the F-statistic across all the regressions is 160.9. See online Appendix B.2 for more details.

${ }^{25}$ We also note that the point estimates when using an adjusted mortality rate in the demand estimation are very similar to the ones we obtain when using the unadjusted rate (see Table D2 in the online Appendix). This is consistent with the fact that we fail to reject the equality of the two mortality rates.

${ }^{26}$ The only changes are: (i) the merger of Hammersmith Hospital and St. Mary's Hospital, which became part of Imperial College Healthcare NHS Trust in 2007, (ii) the opening of the Essex Cardiothoracic Centre at Basildon and Thurrock University Hospitals in July 2007, and (iii) Royal Wolverhampton Hospital started performing a significant number of CABGs only in the second half of 2004 and is therefore excluded from the choice set before that. There are therefore 27 hospitals present in every period of the data. Table D1 in the online Appendix lists the number of hospitals by quarter.

${ }^{27}$ Our demand estimation is capable of handling hospital entry and exit but the stable market structure means we isolate the effect of the change in choice without any potential contamination from change in market structure.

${ }^{28}$ During our study period four private providers of CABG surgery operated (all located in London). However, the cost of CABG surgery is such that any patients who might choose to use a private provider would have to have purchased private insurance before they were diagnosed with a heart problem. The four private providers only performed a very small number of CABGs compared to public hospitals (for
} 


\section{[FIGURE 1 ABOUT HERE]}

In Table 1 we report descriptive statistics for hospitals by (financial) year over the period 2003-2007. The average hospital treated about 500 CABG patients per year, but there is substantial variation in admission rates between hospitals. The number of admissions decreases slightly over time as does the variance across hospitals. ${ }^{29}$ Waiting times fell dramatically over the period. In 2003 and 2004 they were quite long, with averages over 100 days. They decreased substantially in 2005 due to a government policy enforcing waiting time targets (see Propper et al. 2008). ${ }^{30}$ There is considerable variation in waiting times between hospitals, although somewhat less after 2005. The average mortality rate is approximately 1.3 percent for most years with a slight decline towards the end of the sample period. There is substantial variation in mortality rates across hospitals in all years.

\section{[TABLE 1 ABOUT HERE]}

When using the mortality rate and waiting times in the demand estimation, we aggregate the patient-level data to the hospital-quarter level. This provides us with variation over time as well as across hospitals. Using January 2004 until March 2005 as the pre-reform time period and January 2007 to March 2008 as the post-reform time period, we exploit 10 quarters of data, 5 in the pre- and 5 in the post-reform time-period. Descriptive statistics of the quarterly variation for this time period are reported in Table D1 in the online Appendix.

\section{Patient and Area Characteristics}

We measure patient socio-economic status using the Index of Multiple Deprivation (IMD) in the small area (the Middle Super Output Area, MSOA) in which the patient lives. The IMD is a measure of income deprivation of the patient's neighborhood and is the best available metric on patient income in our data. This variable ranks a patient's local neighborhood from richest to poorest. The range is 0 to 1 , with higher values implying higher deprivation. ${ }^{31}$ In the estimation we employ an indicator for whether the IMD in a patient's neighborhood is below the median IMD (0.1), i.e., whether their neighborhood is above the median in

\footnotetext{
example, only 67 CABG proceedures were undertaken in the four private hospitals in 2007). Therefore, we think that our data captures the full choice set of patients.

${ }^{29}$ The total number of CABGs in the UK undertaken in our time period fell due to the increased use of angioplasty (PCI).

${ }^{30}$ This target policy ran most strongly from 2001-2005 i.e. before the choice reform. It has been shown that the fall in waiting times was primarily due to efficiency improvements and did not have any detrimental effect on health outcomes (see Propper et al. 2008).

${ }^{31}$ The IMD is computed by the government for geographical areas that comprise roughly 7,000 individuals. Our data are from England only, which on average is richer than the rest of the UK. Effectively in England the IMD varies over a small range, with most of the sample lying between 0.04 and 0.31 (the 10th and 90th percentile). For more information, see http://www.communities.gov.uk/communities/ research/indicesdeprivation/deprivation10/.
} 
income (since IMD decreases in income). Going forward, we simply refer to this variable as "income."

HES provides a list of co-morbidities at the patient-level. We use these to compute the Charlson index, which weights co-morbidities by their impact on mortality risk (Charlson et al. 1987). The higher the value the greater the patient's risk of mortality (the index for a patient with no co-morbidities has a value of zero). ${ }^{32}$ We use an indicator for whether a patient has a Charlson Index above the median $(\geq 1)$ in the estimation. We refer to this variable as "severity."

Table 2 presents descriptive statistics on the patient characteristics described above. As can be seen, most patients are male and over 60 years of age. There is considerable variation in patients' general health status, with a large fraction of patients for whom several co-morbidities are reported. About 40 percent of patients have a positive value of the Charlson index. Both income and the Charlson index are used in the demand estimation to analyze how the reform differentially affected different groups of patients.

\section{[TABLE 2 ABOUT HERE]}

The bottom two rows of Table 2 contains descriptive statistics on the distances patients travel for their CABG treatments. ${ }^{33}$ We see that the average patient traveled a substantial distance (over 30 kilometers) and that there is a great deal of variation in how far patients traveled for care. It is also notable that there is very little difference in distance traveled between the pre- and post-reform time periods. This could occur if patients sorted themselves to better hospitals postreform within approximately the same distance. In Section V we provide some reduced-form evidence that this is the most likely explanation for the lack of a change in distance traveled.

\section{Structural Estimation}

As outlined in the model exposition in Section II, there are two parts of the model we need to specify: patients' preferences and the constraining process in the pre-reform time period. Post-reform, patients' choices are unconstrained. As a consequence, utility alone drives the choice of hospital. We first describe unconstrained post-reform choice, then move on to pre-reform choice under constraint.

\section{A. Post-Reform (Unconstrained) Choice}

Post-reform utility is (as described earlier in equation (1))

\footnotetext{
${ }^{32}$ For patients in our sample the index takes on values 0,1 and (rarely) $2.60 \%$ of patients have a Charlson Index value of 0 .

${ }^{33}$ We use the patient's 4 digit postcode available in HES to calculate straight line travel distances.
} 


$$
U_{i j}=\bar{U}_{i j}+\varepsilon_{i j}=\beta_{w i} W_{j t}+\beta_{z i} Z_{j t}+f\left(D_{i j}\right)+\xi_{j}+\varepsilon_{i j}
$$

We define $f(\cdot)$ by allowing distance to enter linearly as well as with an indicator for whether the hospital was the closest one in the choice set:

$$
f\left(D_{i j}\right)=\alpha_{d 1} D_{i j}+\alpha_{d 2} \text { Closest }_{i j}
$$

where Closest $_{i j}$ is a dummy equal to one if hospital $j$ is the closest one in the choice set of patient $i$. In what follows, when we write out the utility function we continue to use $f\left(D_{i j}\right)$ to economize on notation. We estimate unobserved hospital quality $\left(\xi_{j}\right)$ by including a set of hospital fixed effects. We also allow for observable heterogeneity in preferences for both waiting times and quality of service in the standard way:

$$
\begin{aligned}
\beta_{z i} & =\bar{\beta}_{z}+\beta_{z} X_{i} \\
\beta_{w i} & =\bar{\beta}_{w}+\beta_{w} X_{i}
\end{aligned}
$$

where $X_{i}$ is comprised of observable patient characteristics on income and illness severity, as described previously in Section III.C.

Based on this utility function, the probability of patient $i$ choosing hospital $k$ in the post-reform time period is given by

$$
\operatorname{Pr}_{i k}^{U N C O N}\left(\Omega_{\text {patient }}\right)=\frac{\exp \left[\bar{U}_{i k}\left(\Omega_{\text {patient }}\right)\right]}{\sum_{j \in J} \exp \left[\bar{U}_{i j}\left(\Omega_{\text {patient }}\right)\right]}
$$

where $\left(\Omega_{\text {patient }}=\beta_{w i}, \beta_{z i}, \alpha_{d}, \xi\right)$ is the vector of coefficients to be estimated pertaining to patient utility and includes the coefficients on waiting times and mortality as well as the interaction terms with observable patient characteristics, the distance coefficients, and the set of hospital fixed effects. $J$ denotes the unconstrained set of all CABG performing hospitals in the UK. ${ }^{34}$ We denote the probability as $\mathrm{Pr}^{U N C O N}$ to distinguish it clearly from the pre-reform choice probability under constraint.

\footnotetext{
${ }^{34}$ We do not limit choice sets based on the location of the patient and hence $J$ contains all CABG performing hospitals and does not vary across patients.
} 


\section{B. Pre-Reform (Constrained) Choice}

We now describe the process by which patient preferences are constrained prior to the reform. In particular, physician utility is distinct from patient utility (as described above, we use the patient index $i$ to describe the physician's utility with regard to the referral of patient $i$ to hospital $j$ ):

$$
V_{i j}=\bar{V}_{i j}+\nu_{i j}=g\left(D_{i j}\right)+\zeta_{j}+\nu_{i j}
$$

where $g\left(D_{i j}\right)$ is a transformation of $D_{i j}$ that reflects the physician's preference for distance to the hospital, $\zeta_{j}$ is a fixed hospital effect denoting (the physician's perception of) hospital quality and $\nu_{i j}$ is an idiosyncratic shock that is iid extreme value. We operationalize $g\left(D_{i j}\right)$ in a similar way as in the patient utility function by including a linear distance term and a dummy for whether the hospital is the closest one, while allowing the parameters for doctors to differ from those for patients. Furthermore, we also include a dummy which is equal to one if the hospital is located within the PCT of the referring physician to capture the fact that it is more likely a contractual arrangement exists for any hospital within the PCT of the GP, thus making a referral to such a hospital easier for the physician prior to the reform. ${ }^{35}$

$$
g\left(D_{i j}\right)=\gamma_{d 1} D_{i j}+\gamma_{d 2} \text { Closest }_{i j}+\gamma_{d 3} \text { WithinPC } T_{i j}
$$

The physician's utility function differs from patient utility in that it does not depend on waiting time or quality. Nonetheless, hospital quality and waiting times can affect pre-reform referrals if the physician allows some degree of choice and therefore the patient is not fully constrained.

We assume that the physician offers multiple hospitals to the patient to choose from. The physician will include hospital $k$ in the consideration set, that is the (potentially limited) set of hospitals patients can choose from, if

$$
V_{i k} \geq \max _{j \in J}\left(V_{i j}\right)-\lambda_{i}
$$

where $\lambda_{i} \geq 0$ and $J$ denotes the full set of hospitals available. $\lambda_{i}$ is a parameter to be estimated and the primary driver of consideration set size, i.e., the degree

\footnotetext{
${ }^{35}$ As noted above, after the reform such incentives did not exist because contracts with specific hospitals were replaced with prospective payments.
} 
to which choice was constrained before the reform. To allow for the reform to differentially affect different groups of patients we allow for heterogeneity in $\lambda_{i}$. Similar to the way we modeled preference heterogeneity we assume

$$
\lambda_{i}=\bar{\lambda}+\lambda X_{i}
$$

where $X_{i}$ is the same set of variables used to capture patient preference heterogeneity, namely the severity of the case and the patient's income level. ${ }^{36} \lambda_{i}$ determines the weight of patient (vs. physician) preferences in the decision-making process. For the case of $\lambda_{i}=0$ only the physician's highest utility hospital is included in the consideration set, i.e., choice is driven entirely by physician preferences. The consideration set formation process collapses to a discrete choice model based solely on physician preferences. At the other extreme, as $\lambda_{i}$ grows larger and $\rightarrow \infty$, more hospitals (eventually all) are included in the consideration set and ultimately patients' preferences are decisive, i.e., patient choices are not constrained by the physician. The consideration set formation process therefore nests both extreme cases of fully constrained and completely unconstrained choice. We denote the constrained set of hospitals offered by the physician by $C S$. The constrained set is a subset of the full choice set $(C S \subseteq J)$ and contains at least one option $(C S \neq \emptyset)$.

The probability that patient $i$ is referred to hospital $k$ in time-period $t$ is given by the product of the probability that hospital $k$ is included in the consideration set by the physician and the probability that the patient picks it from the consideration set:

$$
\operatorname{Pr}_{i k}^{C O N}\left(\Omega_{\text {patient }}, \Omega_{\text {physician }}\right)=\sum_{C S_{k}} \operatorname{Pr}_{i}\left(C S_{k} \mid \Omega_{\text {physician }}\right) \operatorname{Pr}\left(k \mid C S_{k}, \Omega_{\text {patient }}\right)
$$

where $C S_{k}$ denotes all consideration sets that contain hospital $k$. The second probability in the equation above is a function of the patient utility parameters $\left(\Omega_{\text {patient }}\right)$ and is similar to the post-reform choice process without constraints. The only difference is that patient preferences determine the choice of hospital from the subset $C S_{k}$ rather than the full choice set $J$. This yields the following conditional choice probability

\footnotetext{
${ }^{36}$ As outlined above, we allow patients' preferences over quality of service and waiting times to vary with severity and income. Because $\lambda_{i}$ plays the role of constraining patients' ability to react on their preferences regarding both waiting times and mortality (see the discussion of identification in Section IV.C below), we allow the strength of the constraining effect to also vary with the same patient characteristics.
} 


$$
\operatorname{Pr}_{i}\left(k \mid C S_{k}, \Omega_{\text {patient }}\right)=\frac{\exp \left[\bar{U}_{i k}\left(\Omega_{\text {patient }}\right)\right]}{\sum_{j \in C S_{k}} \exp \left[\bar{U}_{i j}\left(\Omega_{\text {patient }}\right)\right]}
$$

The consideration sets in our context are unobserved and the probability for each of the possible sets is driven by the parameters in the physician's utility $\left(\Omega_{\text {physician }}=\gamma_{d}, \lambda_{i}, \zeta_{j}\right)$ :

$\operatorname{Pr}_{i}\left(C S \mid \Omega_{\text {physician }}\right)=\operatorname{Pr}\left(V_{i j \in C S} \geq\left[\max _{j \in J}\left(V_{i j}\right)-\lambda_{i}\right], V_{i j \notin C S}<\left[\max _{j \in J}\left(V_{i j}\right)-\lambda_{i}\right] \mid \Omega_{\text {physician }}\right)$

While $\operatorname{Pr}_{i}\left(k \mid C S_{k}, \Omega_{\text {patient }}\right)$ has an analytical expression, the probability of a particular consideration set occurring has no closed-form solution. For this reason, we take draws from the distribution of physician taste shocks $\nu_{i j}$ and simulate the resulting choice sets. We denote a set of taste shock draws for consumer $i$ as $\left(\nu_{i 1, s_{i}}, \nu_{i 2, s_{i}}, \ldots \nu_{i j, s_{i}}, \ldots\right)$, where $s_{i}$ is an index that denotes one set of simulation draws for consumer $i$. Hospital $k$ is contained in the simulated consideration set $\widetilde{C S}_{s_{i}}$ of patient $i$ (for the set of simulation draws $s_{i}$ ) if

$$
\bar{V}_{i k}+\nu_{i k, s_{i}} \geq \max _{j}\left(\bar{V}_{i j}+\nu_{i j, s_{i}}\right)-\lambda_{i}
$$

For every set of draws, we obtain a different simulated consideration set. Conditional on the simulated consideration set $\widetilde{C S}_{s_{i}}$, we then use $\operatorname{Pr}_{i}\left(k \mid \widetilde{C S}_{s_{i}}, \Omega_{\text {patient }}\right)$ to determine the choice probability of each hospital in the set. This yields the simulated choice probability for hospital $k$ of

$$
\widetilde{\operatorname{Pr}_{i k}^{C O N}}\left(\Omega_{\text {patient }}, \Omega_{\text {physician }}\right)=\frac{1}{S_{i}} \sum_{s_{i}} 1\left(k \in \widetilde{C S}{ }_{s_{i}}\right) \operatorname{Pr}\left(k \mid \widetilde{C S} s_{s_{i}}, \Omega_{\text {patient }}\right)
$$

where $S_{i}$ is the number of draws and $1(\cdot)$ is an indicator function for $k \in \widetilde{C S}_{s_{i}}$.

Note that $\Omega_{\text {physician }}$ influences the choice probability by affecting the probability of a specific consideration set $\widetilde{C S}_{s_{i}}$ occurring. In the case that hospital $k$ is included in the simulated consideration set, the predicted choice probability is given by $\operatorname{Pr}_{i}\left(k \mid \widetilde{C S}_{s_{i}}, \Omega_{\text {patient }}\right)$ and depends on the identities of the other hospitals included in the simulated set. If hospital $k$ is not contained in the simulated set, the choice probability is equal to zero, which is captured by the indicator function. Averaging across simulation draws within each patient $i$ yields the 
simulated choice probability. ${ }^{37}$

The model is estimated by using a simulated method of moments estimator where we set

$$
\sum_{i} \sum_{j}\left[d_{i j}-\operatorname{Pr}_{i j}\left(\Omega_{\text {patient }}, \Omega_{\text {physician }}\right)\right] z_{i j}=0 .
$$

In the equation above $d_{i j}$ denotes a dummy variable which is equal to one for the hospital $j$ patient $i$ was referred to and zero otherwise. $P r_{i j}$ denotes the predicted choice probability, where $P r_{i j}=\widetilde{\operatorname{Pr}_{i j}^{C O N}}$ if patient $i$ was referred pre-reform and $P r_{i j}=P r_{i j}^{U N C O N}$ if the referral occurred post-reform. $z_{i j}$ is a vector of instruments. In our case, the set of instruments is simply equal to a vector of hospital dummies and characteristics as well as interactions of hospital and patient characteristics. Specifically, $z_{i j}$ contains hospital dummies, distance to the hospital, a dummy for the closest hospital, a within-PCT dummy and the two hospital characteristics: quality of service (mortality rate) and waiting times. The latter two are also included interacted with the severity of the case and income. Finally, all instruments are included twice, interacted with both a pre-reform and a post-reform dummy variable. ${ }^{38}$

\section{Identification}

In this section we cover the sources of identification for the model. We first discuss in detail how we separately identify patient and physician preferences. We then turn to the identification of the specific patient preference parameters on waiting time and quality of service.

\section{Separate Identification of Patient and Physician Preferences}

The key source of identification that allows us to separately identify physician and patient preferences is the fact that we observe a change in the process by which consideration sets are formed due to the reform.

It is easiest to think about the logic underpinning our identification strategy by first considering the identification of patient preferences, which is relatively standard because we observe a time-period (post-reform) where choice is liber-

\footnotetext{
${ }^{37}$ In order to avoid discontinuities which occur for the simple frequency estimator described here, we implement a kernel-smoothed frequency estimator. More details are provided in online Appendix C.

${ }^{38}$ The only instrument which appears only for the pre-reform period is the PCT dummy, which only enters physician utility.
} 
ated, and hence only patient preferences drive choice. ${ }^{39}$ This allows us to identify patient preferences from post-reform choice data. ${ }^{40}$ Now consider hospital choice in the pre-reform period. If patient choice pre-reform was unconstrained (and if patient preferences are stable over time) then the post-reform estimates should predict hospital choice before the reform. If instead post-reform preferences do not predict referral patterns in the pre-reform time period, it has to be the case that the way in which referrals were made changed over time. Based on the institutional features of the market (see Section I.B), we capture such differences in referral patterns by assuming that physicians offer patients a limited set of hospitals to choose from prior to the reform. ${ }^{41}$

We assume that these constrained choice sets are formed based on two factors. One is physicians' preferences over hospital characteristics that directly affect the convenience of referrals, and hence their utility. Due to the nature of the contractual arrangements (see Section I.B for details) between referring physicians and hospitals in the pre-reform period, we assume that distance to the hospital as well as hospital fixed effects and whether the hospital is in the physician's PCT enter physician utility directly. Distance captures the convenience of referrals and the hospital fixed effects and whether the hospital is in the physician's PCT capture the physician's past experience with a hospital. The preference weights of these characteristics are identified by the extent to which pre-reform referrals are responsive to the respective hospital characteristics.

The second is the constraining parameter $\lambda$, which is the extent to which the physician allows patient preferences to influence choice, and is the main driver of consideration set size. This is identified through the influence of the variables unique to patient utility on pre-reform choices. The key aspect that helps us identify $\lambda$ is therefore an exclusion restriction on waiting times and mortality rates, which only enter patient utility. Thus, if waiting times and mortality rates have any impact on choice pre-reform, this can only be rationalized by patients being less than fully constrained and hence patient preferences affecting choices even before the reform. The extent to which the sensitivity of referrals to both of these hospital characteristics is lower pre-reform relative to post-reform determines the strength of the constraint.

The two key elements that are crucial for identification are the exclusion restriction on waiting times and mortality, which are assumed not to enter physician utility, and the assumption that patient preferences are stable over time. We now

\footnotetext{
${ }^{39}$ As discussed above (Section I.B), we think of this as physicians having an important role providing information and guiding choice, but acting as patients' agents post-reform, so that choice reflects patients' preferences.

${ }^{40}$ We note that one could estimate the post-reform choice process on its own in the fashion of a standard random coefficient discrete choice model.

${ }^{41}$ We note that this identification strategy is different from other models of consideration set formation, for example Goeree (2008) or Mehta, Rajiv and Srinivasan (2003), where typically the nature of the constraining process does not change over time.
} 
discuss the validity of both assumptions.

\section{EXCLUSION RESTRICTIONS}

Technically, a necessary requirement for our model to be identified is that at least one variable that enters patient utility is excluded from physician utility. If instead we were to include the identical set of variables in both patient and physician utility this would leave the constraining parameter $\lambda$ unidentified. To see why this is so, note that the role of $\lambda$ is to rationalize the change in the sensitivity of referrals to waiting times and mortality. Hence, if we included waiting times and mortality directly in physician utility, then the sensitivity change with respect to these characteristics could be rationalized either by their weights in physician preferences or by a different value of $\lambda$. Therefore, $\lambda$ would not be separately identified.

An alternative way to think about the identification of physician preferences and constraints is to consider the set of instruments used to identify the parameters of the constraining process in the pre-reform period (conditional on having identified patient preferences). As instruments for the pre-reform choice process, we use the same set of hospital characteristics as those that identify preferences in the post-reform period. Given our assumption about the behavior of the physician, hospital dummies and distance respectively serve as instruments for the hospital fixed effects and distance coefficients that enter physician utility directly. Waiting time and quality of service (and their interactions with income and severity) serve as instruments to identify the constraining parameter $\lambda$. In the absence of waiting times and quality entering the physician's utility function, the only way to rationalize the observed sensitivity of referrals to those characteristics is through $\lambda$.

Economically, we exclude waiting times and mortality rate from physician utility because physician utility should only contain variables that influence the physician directly, i.e., those that affect the convenience of referrals. Any variables that affect the physician because he cares about patients' health outcomes reflect physician agency and affect the physician indirectly. We capture these impacts on physician agency by treating these variables as influencing referrals via a loosening of constraints. In other words, a physician who cares about his patients is modeled as allowing a greater degree of choice for the patient and hence allowing patient preferences to influence choice.

We note that our setting is considerably more flexible than extant consideration set models, which are estimated for situations where the constraining regime does not change. Without a change in the decision-making process one needs to have a non-overlapping set of variables enter the preferences and constraints respectively. Any variable that enters both stages is only identified by functional form, due to 
the fact that choice is always driven by parameters in both stages. ${ }^{42}$ In our setting instead, we can estimate preferences from post-reform data and then estimate the constraining process separately using the pre-reform data. This enables us to allow for some (but not complete) overlap in the variables that affect consumers' preferences and constraints. Such an overlap is desirable in our setting where we believe that some characteristics (such as distance) matter to both patients and (pre-reform) to physicians and hence should enter the utility functions of both parties. Our approach allow us to estimate such a model without having to rely on functional form for identification of variables entering patient and physician utility.

Finally, we note that we include the "within-PCT" dummy variable only in physician utility, but not in patient utility, based on the institutional features described earlier. While this helps with identification, it is not necessary to have a variable that only influences physician utility.

\section{Stability of Patient Preferences}

It is crucial for our identification strategy for patient preferences to be stable over time, because this allows us to recover patient preferences from post-reform data and then attribute any change in referral patterns over time to the constraining process. If instead, patient preferences pre-reform are different from post-reform preferences, then we would have to identify both pre-reform patient preferences and constraints from pre-reform data. We believe that the assumption of stable patient preferences is reasonable in our context but provide additional discussion here.

First, we assume that patient preferences regarding waiting times and mortality do not change over time. This assumption might be violated if the mix of patients seeking treatment changes over time. We do see a modest increase in patient severity over time. However, we allow preferences to be a function of severity. Therefore, as long as the change over time in patient severity is reflected in the observed severity measure, this does not pose a problem.

Second, we assume that patient preferences over unobserved hospital quality $\left(\xi_{j}\right)$ are stable over time. One could imagine that as a consequence of the choice reform, hospitals attempted to attract patients by improving quality along dimensions other than waiting times and mortality, and hence this would lead to a change in patient preferences over unobserved hospital quality. We believe that the scope for such behavior in the UK market was very limited in the period we

\footnotetext{
${ }^{42}$ For example, Goeree (2008) assumes that advertising (and interactions of advertising with demographics) only enters the constraining process, but not utility. Other variables such as price and physical product characteristics only affect utility but not the consideration set formation. Similar, Mehta, Rajiv and Srinivasan (2003) model consideration set formation to be a function of whether the product is displayed or featured and familiarity with the store, whereas utility is a function of product dummies and price.
} 
study. Hospitals did not market themselves directly to patients. Published data on performance from the regulatory bodies focused on waiting times and clinical quality. Any changes in unobserved (to the econometrician) quality would have had to be observable to patients or referring physicians in the absence of active marketing activities by hospitals. By contrast, mortality and waiting times, which we do observe, are highly salient indicators. And while mortality may not be known by the patient, it is relatively easy to observe and interpret by the referring physician, who can then communicate this information to the patient.

\section{Endogeneity of Waiting Time and Quality of Service}

Finally, the endogeneity of waiting times and mortality in the utility function (4) is a potential concern. First, it is possible that unobservably better hospitals may have longer waiting times because they attract more patients. By increasing aggregate demand, higher unobserved quality from the patient's $\left(\xi_{j}\right)$ or physician's perspective $\left(\zeta_{j}\right)$ will lead to longer waiting times, so $\operatorname{Corr}\left(W_{j t}, \xi_{j}\right) \neq 0$ (or $\left.\operatorname{Corr}\left(W_{j t}, \zeta_{j}\right) \neq 0\right)$ implies that we will be unable to obtain a consistent estimate of the effect of waiting times on hospital choice $\left(\beta_{w, i}\right)$ without addressing this issue. The issue is very similar to the endogeneity of the price coefficient commonly encountered in the empirical literature in industrial organization. In that context, products with higher unobserved quality will have greater demand, which in turn leads to higher prices. An analogous mechanism will drive waiting times up in the fixed price (and capacity constrained) environment of the English NHS. In other words, rationing through waiting times plays a similar role to the price mechanism in other markets. This will lead to waiting times being positively correlated with unobserved hospital quality.

Second, a related concern also applies to our measure for quality of service, because hospitals which treat a larger number of cases might also exhibit higher quality. Such a relationship between volume and quality is well established and is likely to also apply to our setting. ${ }^{43}$ The volume-quality channel is problematic in our context, because hospitals with higher unobserved quality will attract more patients, which in turn will lead to higher quality and hence a correlation of quality of service (mortality rate) with unobserved quality $\xi_{j}\left(\zeta_{j}\right)$.

In principle these endogeneity problems can be addressed either by using instrumental variables or by controlling for unobserved heterogeneity via fixed effects to absorb the variation in unobserved quality. As there are no obvious good instruments for waiting times and quality of service, we employ a fixed effects approach. ${ }^{44}$ Specifically, we estimate a separate hospital fixed effect as part of both patient and physician utility. This allows for unobserved hospital quality

\footnotetext{
${ }^{43}$ There is a very large literature on the "volume-outcome" relationship in health care. Some papers from that literature are Birkmeyer et al. (2002), Silber et al. (2010), and Halm, Lee and Chassin (2002).

${ }^{44}$ One could consider employing the commonly used strategy of using values of the endogenous variable(s) from another (product or geographic) market. For example, we could consider using waiting times
} 
to differentially affect the pre- and post-reform periods, since quality effects on physician utility affect choice only in the pre-reform period. ${ }^{45}$

\section{Reduced-Form Evidence}

Before proceeding to the structural analysis, we look at patterns in the data to provide some simple empirical evidence on whether patients became more responsive to hospital quality after the reform. We start by running a simple linear regression of aggregate market shares on mortality rates to examine the impact of the introduction of choice on the responsiveness of market shares to the mortality rate. This allows us to illustrate some of the main patterns in the data in a simple way. We aggregate the patient-level data to the hospital-quarter level. The mortality rate is also defined at this level. We estimate separate OLS regressions with hospital fixed effects for the pre- and post-reform time periods.

The results are reported in Table 3, columns (1) and (2). These show that prereform higher quality hospitals did not have significantly larger market shares. Post-reform, however, a lower mortality rate is significantly associated with a higher market share. This provides initial suggestive evidence that the elasticity of demand with respect to quality rose due to the introduction of choice. It is possible that this relation has nothing to do with choice but is an artifact of the distribution of market shares and mortality rates, which are unrelated to the introduction of patient choice. We test this by implementing a placebo test in which we replicate the same regressions of columns (1) and (2) using emergency CABG cases instead of elective ones. Choice does not play a role for emergency admissions: patients are simply taken to the nearest suitable facility. Therefore, if we see a change in the correlation of market shares with mortality for emergency admissions, it should not be due to the reform. Examining the results in Table 3 , columns (3) and (4), we see that hospital mortality rates have no statistically significant impact on emergency CABG market shares either pre- or post-reform.

\section{[TABLE 3 ABOUT HERE]}

An alternative way of analyzing the issue of an increased sensitivity of demand

for other procedures at the same hospital as instruments. As a robustness check we implemented such an approach and find that our results are robust to instrumenting CABG waiting times (on top of including hospital fixed effects) with waiting times for other procedures (due to the non-linearity of the demand model, we implement this regression via a control function approach). However, these instruments are not without problems, as unobserved quality may be correlated across procedures. For instance, general hospital reputation might affect demand similarly across procedures. Furthermore, such an IV strategy is harder to implement for mortality rates, since quality measures are more difficult to compare across different procedures. See for example Gravelle et al. (2012). In addition, NHS hospitals do not operate in multiple, widely dispersed locations. Therefore the common strategy of using values of the endogenous variable from a distant market is not a good fit for our situation.

${ }^{45}$ We note that ideally we would want to control for unobserved quality even more rigorously by including a separate fixed effect for each hospital/quarter combination. However, other hospital characteristics, namely waiting times and the mortality rate, are defined at this level and there impact on choice would hence not be identified if hospital/quarter fixed effects were included. 
is to look directly at the expected (hospital-level) mortality rate that the average patient faces. In the first row of Table 4 we report the average mortality rate a patient faces pre- and post-reform. We find a substantial fall of about 30 percent (0.4 percentage points) in the mortality rate post-reform. This fall might occur for a number of reasons. For example, it could be due to a secular downward trend in the mortality rate across all hospitals, or to hospitals in high population areas improving more (so more patients are treated at better facilities without necessarily exercising choice), or to patients deliberately choosing higher quality hospitals.

\section{[TABLE 4 ABOUT HERE]}

To try to identify the impact of choice, we report the change in the mortality rate separately for patients who visited the nearest hospital and patients who bypassed the nearest hospital and traveled further. If the drop in average mortality is simply due to an overall downward secular trend, we should not see differences in mortality between patients who visited the nearest hospital and those who bypassed it. Similarly, if the decrease in mortality is due to the fact that patients simply had better hospitals closer by after the reform, we should see most of the drop explained by the group of patients who visited the nearest hospital. Examining the patterns in Table 4 we find that the opposite is true. The drop in mortality among patients bypassing the nearest hospital is more than twice as large as the drop for patients who visit the nearest hospital. In other words, we observe larger declines in mortality for patients who decide not to use their local hospital. Consistent with the results in Table 3, this supports the idea that these patients were not simply lucky that the local hospital improved its quality but, rather, that they sought better hospitals once they were allowed a choice of provider.

These patterns in the data provide some initial evidence suggesting that the introduction of patient choice via the reform increased the responsiveness of demand to cross-hospital differences in quality.

\section{Estimation Results: Structural Model}

We first report the estimation results from our model of choice and constraints, then report how they translate into patient and hospital level elasticities of demand.

\section{A. Parameter Estimates}

The results from the estimation are reported in Table 5. For economy of exposition, the (large number of) fixed effect estimates are not reported. We find that patients care about distance to the hospital and both of the distance coefficients 
are highly significant in the patient utility function. The results also show that patients dislike higher mortality rates, i.e., lower quality. The effect is stronger for more severely ill patients as well as for lower income groups. The latter effect, however, is only significant at the 10 percent level. In terms of sensitivity to waiting times, we find an insignificant effect for low severity and low income patients. There is some evidence that higher income households care less about waiting times. ${ }^{46}$

\section{[TABLE 5 ABOUT HERE]}

In terms of physician preferences, we find that both distance terms as well as the within-PCT dummy are highly significant. We also find that most patients are severely, in fact fully, constrained before the reform took place. For low severity cases (regardless of income) $\lambda$ is estimated to be equal to zero, which implies that no choice was offered by the physician and patient preferences did not influence referrals. Only for high severity cases do we find a positive coefficient on $\lambda$.

\section{B. Elasticities of Demand}

As the primary focus on the paper is on the quality of care and we find only weak (mostly insignificant) results for sensitivity with respect to waiting times post-reform, we focus on the elasticity of demand with respect to the mortality rate. We start by computing elasticities for individual patients with respect to the mortality rate. Analyzing individual-level elasticities is helpful in our context to get a better sense of how strongly different patient groups were affected by the relaxation of the constraint on choice. We then compute hospital-level demand elasticities (by aggregating up changes in individual choice probabilities) to assess the impact on the demand faced by hospitals.

\section{Patient-level Elasticities and Consideration Set Size}

Panel A of Table 6 reports the sensitivity of choice probabilities to changes in the mortality rate for different groups of patients pre- and post-reform. Bootstrapped standard errors are in parentheses. To simulate patient-level elasticities,

\footnotetext{
${ }^{46}$ The lack of an effect of waiting times is probably due to the large fall in waiting times that occurred just prior to the full roll out of the choice program in 2006. In 2001 the government instituted an aggressive national policy (dubbed "targets and terror") to reduce waiting times which had considerable success in lowering waiting times before the choice reforms (Propper et al. 2010) and may have meant that waiting times became less salient to patients. See also Gutacker et al. (2015) who find no effect of waiting times on demand for hip replacement surgery in England between 2010 and 2013. Beckert, Christensen and Collyer (2012) do find an effect of waiting times, but for a much simpler orthopaedic procedure for which mortality rates are very low. Our estimated net effect of waiting times for high income patients (i.e. adding the waiting time coefficient and the interaction of waiting times and high income) is positive, but only marginally significant ( $\mathrm{p}$-value 0.055 ). This either means that high income patients prefer longer waits (perhaps in order to arrange their affairs before entering hospital), or may indicate some residual endogeneity.
} 
we compute a one standard deviation shift in the mortality rate for each hospital and compute the change in choice probabilities entailed by this change for each patient in the relevant time period. We then average the changes across patients and hospitals. We also compute the average consideration set size pre-reform to give a sense of how constrained patients were in their choices. To examine the impact of patient characteristics, we simulate the reactions of all patients preand post-reform to a quality change for all four possible permutations of severity and income. (For each simulation we set all patients to have the same characteristics.) This allows us to isolate elasticity differences that are due to patient characteristics from any other factors, such as geographic location, that might be correlated with patient characteristics.

\section{[TABLE 6 ABOUT HERE]}

The first column shows that, pre-reform, choice was fully constrained for low severity patients regardless of income. This leads to a complete lack of responsiveness of referrals to quality for this group of patients, as shown in the second column. For high severity cases, irrespective of income, choices were not fully constrained. High severity patients in both income groups were offered an average of 1.61 hospitals. This leads to a non-zero, but small, sensitivity to quality pre-reform. The third column shows that the liberation of choice has a substantial impact for all four demographic groups. Sensitivity changes by 1.2 for low severity and low income cases and by 1.5 for high severity and low income cases. The respective increases for high income cases are of the order of 0.6 and 0.9. Post-reform, higher income households have a lower sensitivity to quality than low income households. Interestingly, in contrast to fears that choice-based reforms harm individuals from lower income groups (see Cookson, Laudicella and Donni 2013), our analysis suggests that households from more deprived areas benefitted slightly more from the reform.

\section{Hospital-Level Elasticities}

To assess the impact of the choice reform on the quality provision by hospitals, the hospital-level elasticities are the most crucial factor. If the demand that hospitals face becomes more elastic with regard to quality, then relaxing the constraints on choice was successful in increasing hospitals' incentives to provide higher quality. We examine hospital-level demand sensitivity by simulating a one standard deviation change in mortality for each hospital in the choice set and computing the percentage change in the hospital's market share. The responsiveness to a change in mortality differs across hospitals as a function of the density of patients in the local area, the demographic composition of the local population, and the locations of other hospitals. Panel B of Table 6 reports the distribution of elasticities across all hospitals.

The first column shows that when constraints on choice are relaxed post-reform 
a one standard deviation increase in the mortality rate leads to a 4.46 percent drop in market share for the average hospital. This compares to a much smaller decrease of 0.82 percent before the reform. The standard errors indicate this change is statistically significant. The highest quartile of the elasticity distribution pre-reform lies below the lowest post-reform. The distribution of hospital elasticities also shows substantial heterogeneity in the impact of the reform across hospitals. The additional market share loss after the reform is 4.37 at the 25 th percentile and 2.04 at the 75 th percentile of the distribution of elasticity changes.

Overall, the results suggest that relaxing the constraints on choice substantially increased hospitals' incentives to improve quality. In percentage terms, demand at the average hospital became over five times more responsive to quality. While the magnitude of the elasticity is not especially large in absolute terms, the reform led to a large increase in demand responsiveness from what had been a very low level. Further, there is large heterogeneity in the effect: many hospitals experienced substantial changes in the demand elasticities they faced.

\section{Policy Evaluation}

We provide an evaluation of the impact of allowing free choice in several steps. We first estimate the number of lives that were saved by allocating patients to better hospitals post-reform and analyze the consumer welfare gains due to the relaxation of choice constraints. These calculations evaluate effects of the reform under the assumption that hospitals did not react to the change in demand conditions, so the survival and welfare gains are purely due to sorting of patients across hospitals. We then proceed to an analysis of how much the competitive environment changed with the introduction of the reform. Finally, we provide evidence which shows that hospitals seem to have reacted to the change in demand conditions as intended by policy makers.

In all but the last step, we simulate counterfactuals in order to quantify the impact of increased choice. Contrary to many other applications in the empirical industrial organization literature, we do not simulate changes caused by a hypothetical policy, but instead simulate behavior for the post-reform population under the assumption that the reform had not taken place. This allows us to leverage the structure of our model to evaluate and quantify the effects of the policy change.

\section{A. The Impact of Choice on Patient Survival}

An obvious and very direct measure by which to evaluate the policy is the impact on the probability of survival following a CABG. We assess this by calculating how many more patients would have died had the reform not been implemented, 
i.e., if patients in the post-reform time period were still subject to pre-reform choice constraints and therefore choosing according to pre-reform parameters.

Formally, we implement the analysis in the following way. The ex-ante mortality probability of any particular patient $i$ in time-period $t$ is given by

$$
\begin{aligned}
E\left(\text { Mortality }_{i}^{U N C O N}\right) & =\sum_{j} \operatorname{Pr}_{i j}^{U N C O N}\left(\Omega_{\text {patient }}\right) \cdot E(\text { Mortality } i \mid \text { Choice }=j) \\
E\left(\text { Mortality }_{i}^{C O N}\right) & =\sum_{j} \operatorname{Pr}_{i j}^{C O N}\left(\Omega_{\text {patient }}, \Omega_{\text {physician }}\right) \cdot E(\text { Mortality } i \text { Choice }=j)
\end{aligned}
$$

where the two rows define the mortality probability under unconstrained and constrained choice respectively. ${ }^{47}$ Note that the two expressions differ only in the choice probability. The first term in both equations denotes the probability of visiting hospital $j$, which can be computed from the demand model estimates. For the case of unconstrained choice this is determined by patient preferences. In the constrained case physician preferences together with patient preferences influence choice. Mortality $y_{i}$ denotes an indicator variable which is equal to one if the patient dies during the surgery. The second term in both lines denotes the conditional mean of this variable, which is equal to the hospital-specific mortality rate. $^{48}$

To obtain the expected difference in mortality across all patients we compute

$$
E\left(\Delta \text { Mortality }_{\text {total }}\right)=\sum_{i \in \text { PostReform }}\left[E\left(\text { Mortality }_{i}^{C O N}\right)-E\left(\text { Mortality }_{i}^{U N C O N}\right)\right]
$$

In other words, we sum the changes in mortality probability for each patient in the post-reform period when choice is constrained relative to when there are no constraints. The latter constitutes the actual state of the world post-reform while the former is a counterfactual scenario in which the reform never happened and constraints are still in place.

The results are reported in Table 7, Panel A. We estimate that 4.2 fewer patients would have survived had the reform not been implemented in 2005. This number is calculated over the entire five post-reform quarters used in the estimation and

\footnotetext{
${ }^{47}$ In this context we think of the ex-ante probability as the probability of death before both the error terms of the choice process and the error term influencing survival are realized, i.e. the patient has not decided which hospital to visit and we do not yet know the patient-specific shock to the mortality outcome.

${ }^{48}$ The hospital-specific mortality rate is identical to the mortality variable used as quality indicator $Z_{j t}$ in the demand model.
} 
corresponds to 3.3 lives saved on a annual basis. The changes amount to about 0.02 percentage points or a 3 percent decrease in the mortality rate in the relevant time period. If we adopt the $\$ 100,000$ benchmark of Cutler and McClellan (2001) for the value of a year of life, and assume that CABG survivors' lives are extended by 17 years (van Domburg, Kappetein and Bogers 2009), the beneficial effects of the pro-competition reforms are about $\$ 5.6$ million per year in terms of value of life-years saved. ${ }^{49}$

\section{[TABLE 7 ABOUT HERE]}

\section{B. Changes in Patient Welfare}

Next we compute the welfare changes due to the removal of restrictions on choice. We simulate a post-reform scenario where the constraints are still in place as the counterfactual. The comparison with the unconstrained choice scenario allows us to quantify the welfare effect of the reform on the post-reform pool of patients. Expected consumer surplus (in utils) for consumer $i$ when choice is unconstrained can be expressed using the standard formula:

$$
E\left(\operatorname{Surplus}_{i}^{U N C O N}\right)=E\left[\max _{j \in J}\left(\bar{U}_{i j}+\varepsilon_{i j}\right)\right]
$$

For the case of constrained choice utility is still given by the same patient utility function but choices are now determined by both patient preferences and the constraining forces of the physician's influence on the referral. Expected utility is equal to:

$$
E\left(\operatorname{Surplus}_{i}^{C O N}\right)=E\left[\max _{j \in C S_{i}}\left(\bar{U}_{i j}+\varepsilon_{i j}\right)\right]
$$

This expression differs from the unconstrained case only in the choice rule: the chosen hospital is the utility maximizing hospital from the constraint set $C S_{i}$ rather than the full set $J{ }^{50}$

Due to the iid extreme value assumption on the error term (see Small and Rosen 1981, Train 2003) we can re-write the surplus expressions above (up to an arbitrary constant) as a logit-inclusive value:

\footnotetext{
${ }^{49} 3.3 \times 17 \times 100,000=5,610,000$

${ }^{50}$ As before, $J$ denotes the set of all CABG performing hospitals in the UK and is therefore not patient-specific. The constraint set $C S_{i}$ instead is specific to patient $i$.
} 


$$
\begin{aligned}
E\left(\text { Surplus }_{i}^{U N C O N}\right) & =\ln \sum_{j \in J} \exp \left(\bar{U}_{i j}\right) \\
E\left(\text { Surplus }_{i}^{C O N}\right) & =\ln \sum_{j \in C S_{i}} \exp \left(\bar{U}_{i j}\right)
\end{aligned}
$$

The welfare calculation for the unconstrained case is standard and the expression above can be computed directly from the patient utility function conditional on the estimated model parameters (see, e.g., Nevo 2003, Ho 2006). The constrained case is more difficult to compute because the consideration set $C S_{i}$ is unobserved. We therefore simulate consideration sets conditional on our parameter estimates (in a similar manner as we simulated consideration sets in the estimation). Specifically, we simulate the physician taste shocks $\left(\nu_{i j}\right)$ that determine which hospitals are included in $C S_{i}$. For a given set of draws, we then compute the associated consideration set and the expected surplus derived from choice from this set. Averaging over draws allows us to compute the expected surplus for each patient $i$.

The average change in surplus per patient is simply equal to the difference between the two expressions above, averaged across patients:

$E\left(\Delta\right.$ Surplus $\left._{i}\right)=\frac{1}{\# \text { Patients PostReform }} \sum_{i \in \text { PostReform }} E\left(\right.$ Surplus $\left._{i}^{\text {UNCON }}\right)-E\left(\right.$ Surplus $\left._{i}^{C O N}\right)$

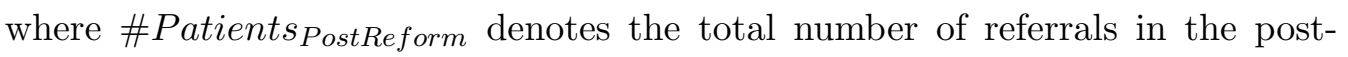
reform time-period.

We find that the freeing of choice led to an average increase of 1.04 units in expected utility. ${ }^{51}$ Since there is no price mechanism in this market (and therefore no price coefficient in the demand model) we cannot directly translate the welfare change from utils into a dollar value. However, we can express the gain in terms of the hospital characteristics in the utility function. If we compare the gains to the preferences over distance, we find that the welfare effect of the reform corresponds to a 15 kilometer reduction in travel distance. ${ }^{52}$ This corresponds to around half of the average travel distance of 30 kilometers reported in Table 2. We

\footnotetext{
${ }^{51}$ Our calculations are for impacts on consumer welfare alone, not social welfare. Nonetheless, we note that these calculations assume the same amount of spending for CABGs under the counterfactual as the actual post-reform patterns. This is likely to be the situation. Since there is no difference between the actual post-reform case and the counterfactual in the number of CABG cases, and since the fixed payment per CABG case is the same across hospitals, there is no difference in total spending between the actual post-reform case and the counterfactual.

${ }^{52} 1.04 /(-6.98)=-0.149$, where -6.98 is the coefficient on distance in the patient utility function. Distance in the regression is defined in units of 100 kilometers.
} 
then translate the welfare estimates into a dollar value using additional data from outside of the model. A back of the envelope calculation to monetize the implied travel time reduction yields a welfare effect of approximately $\$ 6,226$ per person. ${ }^{53}$ We note that a similar calculation based on mortality rates and the statistical value of life yields a much larger value $(\$ 300,900$ per person) and we therefore remain cautious with respect to the reliability of the monetary conversion. ${ }^{54}$

Relative to the change in survival reported above, the welfare calculation provides a much broader assessment of the impact of the reform on patients. All components of consumer preferences including quality, waiting times, distance, as well as hospital fixed effects and idiosyncratic patient taste shocks are suppressed by the pre-reform constraints. Hence when constraints are removed, the patient's ability to choose based on her preferences leads to an increase in welfare. To further understand the source of the welfare change, we proceed to decompose the impacts of the different utility components that are suppressed by the choice constraints. We implement the decomposition by imposing counterfactual constraints to patient choice that are aligned or misaligned with patient preferences along various dimensions in order to isolate the impact of freeing up choice on the different components of patient preferences.

In a first step we take the estimated physician utility function, but replace the hospital fixed effects in his utility function with the patient's set of hospital fixed effects. We then estimate the welfare impact of post-reform patients being constrained by a physician with these preferences. Relative to the previous welfare comparison, the welfare decrease from imposing the constraints has to be smaller now, because the constraints are less "hurtful" to the patient due to the fact that patient and physician utility are more aligned and hence the physician is more likely to offer a hospital that the patient would have chosen herself. Comparing the welfare change due to the removal of constraints in this case with our baseline welfare change calculation, we find that the change is 17 percent smaller. Hence 17 percent of the welfare change is due to the patient being able to react to her preference over hospitals' unobserved quality.

Next, we further align physician and patient preferences by endowing the physi-

\footnotetext{
${ }^{53}$ The UK Department of Transport estimates that it takes approximately 4 minutes to travel a mile in the ten largest areas in Britain during the time period of our study http://webarchive.nationalarchives.gov.uk/20110507043012/http://dft.gov.uk/pgr/statistics/ datatablespublications/roads/congestion/urban/cgn0301.xls. This translates into approximately 37 minutes to travel $15 \mathrm{~km}$ (9.32 miles). Gowrisankaran, Nevo and Town (2015) estimate from that a 1 minute increase in travel time to hospitals reduces consumer surplus by $\$ 167$. Applying this to the travel time yields a welfare effect of $\$ 6,226.14$ per person.

${ }^{54}$ Taking into account heterogeneity in the mortality coefficient, we calculate an average per patient gain in units of mortality (measured between 0 and 1 ) of 0.177 . Multiplying by the value of a statistical life $(\$ 100,000$ per life year $\times 17$ additional years of life, as before) gives us $0.177 \times 100,000 \times 17=300,900$. Fundamentally, the reason this number differs from the number derived from travel distance is because there is no price coefficient in our model (since NHS care is free of charge). As a consequence, the back of the envelope estimates differ due to differences in the numbers we import to monetize the welfare gain, as well as differences in the distance and mortality rate parameter estimates in our model.
} 
cian with the same preferences over distance, waiting time, mortality and unobserved quality as the patient. Thus the only remaining difference between the two parties are their idiosyncratic taste shocks. Aligning the deterministic part of utility in this way further reduces the welfare change from removing the constraints by 11 percent. The remaining (residual) difference in welfare with and without constraints constitutes 72 percent of the total welfare change and is due to the patient's ability to respond to her idiosyncratic random taste shocks. Idiosyncratic taste shocks could be, for example, whether a hospital is located near to a patient's family members, or if a patient particularly values being treated by a surgeon at a particular hospital.

\section{Change in the Competitive Environment}

The welfare analysis and the change in survival calculate only the changes that are achieved by reallocating patients, i.e. they do not take into account any supply side adjustments by hospitals to the new demand conditions. We now examine the further improvements that could be achieved if the reform also provided incentives for hospitals to improve quality.

First, we undertake a counterfactual calculation to get a sense of the magnitude of the relaxation of choice constraints on hospitals' incentives. We look at how hospital market shares in the pre-reform period would have been different if patient choices had occurred without constraints, i.e., using the estimated post-reform parameters. This allows us to compute how much re-shuffling of market shares would have happened had patients had free choice earlier. When implementing this counterfactual, we hold everything fixed except for the choice parameters. In other words, the same set of patients is exposed to the same set of hospitals as in the actual pre-reform choice situation. We do not allow hospitals to adjust to the changes in demand caused by the removal of constraints. Holding hospital quality fixed is helpful because any movement we see in market shares in actual post-reform referrals will be due to both demand changes and hospitals' responses to these. Our counterfactual allows us to isolate the former effect to assess the pressure on hospitals from the reform, for a given quality level. The magnitude of the re-shuffling of market shares is therefore a valuable metric of how much incentives to improve quality changed for hospitals. It should also be noted that due to the absence of an outside option the simulated changes in market shares have to cancel out across hospitals. We are therefore quantifying a re-allocation of a given set of patients.

To describe this, we report the change in market share at various percentiles of the distribution of changes in Panel B of Table 7. We find that the introduction of choice had a significant impact on many hospitals. At the 25 th percentile of the distribution hospitals would have experienced a roughly 15 percent decrease while at the 75 th percentile hospitals experienced around a 15 percent increase 
in market-share. At the mean and median, the change is close to zero due to the fact that the changes in market-shares across hospital sum to zero.

\section{Supply-Side Response}

Having established that the introduction of choice led to a substantial increase in demand elasticities faced by hospitals, we now provide some evidence for a supply-side response to this change in the competitive environment. We expect that hospitals in areas where demand became more elastic to improve their quality more than other hospitals. We test this hypothesis by regressing the change in the mortality rate on the change in hospitals' elasticity of demand with respect to quality.

This approach mirrors the difference-in-difference estimation conducted in Gaynor, Moreno-Serra and Propper (2013) and Cooper et al. (2011). In these papers, a change in the mortality rate is regressed on cross-sectional variation in hospital market structure. ${ }^{55}$ The argument is that the expansion of choice will have a stronger impact in areas with a higher density of competing hospitals. Using a measure of concentration, like the Herfindahl Index, constitutes a reduced-form way of capturing that the elasticity of demand is expected to change relatively more in high concentration areas. Here we are instead able to compute demand responsiveness directly from the model estimates, rather than having to use hospital concentration as a proxy. We are hence able to use a more direct measure of the change in competitive environment than the previous literature.

We use the observations on the 27 hospitals that are present in all periods of the data and use the change in demand responsiveness reported in the lower panel of Table 6 as the regressor. ${ }^{56}$ We estimate the following OLS regression:

$$
\Delta \text { Mortality }_{j}=\phi_{0}+\phi_{1} \Delta \text { Elasticity }_{j, \text { Mortality }}+e_{j}
$$

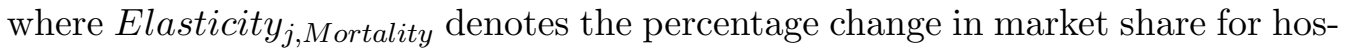
pital $\mathrm{j}$ when the mortality rate is increased by one standard deviation. For ease of interpretation, we use the absolute value of the elasticity in the regression. We note that, due to the differenced nature of the regression, any time-invariant factor that might differ across hospitals does not pose a threat to a causal interpretation. However, any time-varying factor that is correlated with the change in the demand elasticity could lead to a bias in the estimation. While there is no other obvious change over time that might correlate with the change in the competitive environment (see also the discussion in Gaynor, Moreno-Serra and Propper (2013) and Cooper et al. (2011)) we cannot fully rule out such confounds.

\footnotetext{
${ }^{55}$ For the most part different versions of an HHI index are used in these papers. However both papers show robustness to a host of definitions of the measure of market structure.

${ }^{56}$ There were two new entrants and one merger over our period. See footnote 26 for details.
} 
The results are reported in Panel $\mathrm{C}$ of Table 7 . We find a negative and significant impact of the change in the demand elasticity on the change in the mortality rate. In other words, hospitals whose demand became more responsive to quality improved quality disproportionately more than other hospitals (by lowering the mortality rate). To get a sense of the magnitude of the coefficient, consider the change in the demand elasticity for the median hospital, 3.09, as reported in Table 6 . This shift implies a drop of 1.01 in the mortality rate. This estimation of the effect of the reform on mortality at the median hospital is slightly larger than improving quality by one standard deviation in the across-hospital distribution and suggests that freeing up patient choice elicited a supply side response by hospitals that improved patient survival. In terms of magnitude, our point estimate implies that competition could have played a significant role in the overall drop in the CABG mortality rate from 2003 to $2007 .{ }^{57}$

We also undertake an exercise to illustrate what the welfare effect of quality improvement due to supply side response could be. We do this by simulating choice under the scenario that mortality rates had not changed due to the reform. In order to obtain counterfactual mortality rates in the absence of the reform, we assume that the change in mortality for each hospital is equal to the intercept in the regression above, $\phi_{0}$. We hence assume that without the reform, no change in elasticity would have taken place and therefore $\Delta$ Elasticity $_{j, \text { Mortality }}=0$, which implies that the expected change in mortality does not depend on the slope parameter $\phi_{1}$. We then simulate the change in welfare when applying constraints to the post-reform patients (as we did in Section VII.B) and setting the mortality rates to the higher counterfactual levels. We find a decrease in welfare that is 8 percent larger than the welfare change computed earlier from only the removal of constraints. ${ }^{58}$ This provides evidence that there is a further component of welfare improvements due to the supply-side reaction to the reform.

While these results are interesting, they do not come from a formal model of supply-side behavior and are based on only 27 observations. We therefore regard them as suggestive. To fully explore the supply response we would need to estimate a fully specified structural model including the supply side: we leave this for future research.

\section{Summary and Conclusions}

This paper takes advantage of a "natural experiment" in the English National Health Service that introduced patient choice among hospitals to examine the

\footnotetext{
${ }^{57}$ We note that a volume-outcome effect (as discussed earlier) would lead the estimates to go the other way, since high mortality hospitals are those with the largest changes in their elasticities and the biggest improvement in quality. Therefore to the extent there is a volume-outcome effect, we may underestimate the supply response to the reform.

${ }^{58}$ The welfare calculation in Section VII.B was based on a simulated removal of constraints, holding mortality rates constant.
} 
effect on patient behavior and supplier responses to that behavioral change. We evaluate whether increased choice resulted in increased elasticity of demand faced by hospitals with regard to two central dimensions of hospital service: clinical quality of care and waiting times. Using detailed patient-level data, we estimate a structural model of patient choices and constraints. On the methodological side we show how to explicitly model the choice constraints imposed by the pre-reform referral system.

We find substantial impacts of the removal of restrictions on patient choice. Patients are more responsive to the clinical quality of care at hospitals. Most patient groups are not more responsive to waiting times. There is, however, heterogeneity in these impacts. The more severely ill and those from low income areas benefit more from the removal of constraints. This increased demand responsiveness alone led to a reduction in mortality and an increase in patient welfare. The elasticity of demand faced by hospitals also increased post-reform. This gave hospitals incentives to improve their quality of care and we find evidence that hospitals responded strongly to the enhanced incentives due to increased demand elasticity.

Overall, this paper provides evidence that a reform that removed constraints on patient choice worked: patient flows were more sensitive to clinical quality and patients went to better hospitals. And, in contrast to fears that these pro-choice reforms would only benefit the better off, we find no evidence of this. This suggests that there is potential for choice based reforms to succeed and for competition in health care to enhance quality.

\section{REFERENCES}

Andrews, R. L., and T. C. Srinivasan. 1995. "Studying Consideration Effects in Empirical Choice Models Using Scanner Panel Data." Journal of Marketing Research, 32(1): 30-41.

Baker, Laurence C., M. Kate Bundorf, and Daniel P. Kessler. 2015. "The Effect of Hospital/Physician Integration on Hospital Choice." National Bureau of Economic Research Working Paper 21497.

Beckert, Walter. 2015. "Choice in the Presence of Experts." Birkbeck College, University of London Birkbeck Working Papers in Economics and Finance 1503.

Beckert, Walter, Mette Christensen, and Kate Collyer. 2012. "Choice of NHS-funded Hospital Services in England." The Economic Journal, 122(560): 400-417.

Besley, Timothy, and Maitreesh Ghatak. 2003. "Incentives, Choice, and Accountability in the Provision of Public Services." Oxford Review of Economic Policy, 19(2): 235-249.

Birkmeyer, John D., Andrea E. Siewers, Emily V.A. Finlayson, Therese A. Stukel, F. Lee Lucas, Ida Batista, H. Gilbert Welch, 
and David Wennberg. 2002. "Hospital Volume and Surgical Mortality in the United States." New England Journal of Medicine, 346: 1128-1137.

Blöchliger, Hansjörg. 2008. "Market Mechanisms in Public Service Provision." OECD Economics Department Working Papers, No. 626. Organization for Economic Cooperation and Development, Paris, France.

Bronnenberg, B. J., and W. R. Vanhonacker. 1996. "Limited Choice Sets, Local Price Response and Implied Measures of Price Competition." Journal of Marketing Research, 33(2): 163-173.

Capps, C., D. Dranove, and M. Satterthwaite. 2003. "Competition and Market Power in Option Demand Markets." RAND Journal of Economics, 34(4): 737-763.

Charlson, Mary E., Peter Pompei, Kathy L. Ales, and C.Ronald MacKenzie. 1987. "A new method of classifying prognostic comorbidity in longitudinal studies: Development and validation." Journal of Chronic Diseases, 40(5): $373-383$.

Cookson, R., M. Laudicella, and P. L. Donni. 2013. "Does Hospital Competition Harm Equity? Evidence from the English National Health Service." Journal of Health Economics, 32(2): 410-422.

Cooper, Z., S. Gibbons, S. Jones, and A. McGuire. 2011. "Does Hospital Competition Save Lives? Evidence from the English Patient Choice Reforms." Economic Journal, 121(554): F228-F260.

Cutler, D. M., and M. McClellan. 2001. "Is Technological Change in Medicine Worth It?" Health Affairs, 20(5): 11-29.

Dafny, Leemore, Kate Ho, and Mauricio Varela. 2013. "Let Them Have Choice: Gains from Shifting Away from Employer-Sponsored Health Insurance and toward an Individual Exchange." American Economic Journal: Economic Policy, 5(1): 32-58.

Farrar, Shelley, Jon Sussex, Deokhee Yi, Matt Sutton, Martin Chalkley, Tony Scott, and Ada Ma. 2007. "National Evaluation of Payment by Results - Report to the Department of Health." Health Economics Research Unit, University of Aberdeen Report. http://www.abdn.ac.uk/heru/ documents/pbr_report_dec07.pdf (accessed April 27, 2010).

Gaynor, Martin, and Robert J. Town. 2012. "Competition in Health Care Markets." In Handbook of Health Economics. Vol. 2, , ed. Thomas G. McGuire, Mark V. Pauly and Pedro Pita Barros, Chapter 9, 499-637. Amsterdam and London:Elsevier North-Holland. 2012.

Gaynor, Martin, and William B. Vogt. 2003. "Competition Among Hospitals." Rand Journal of Economics, 34(4): 764-785.

Gaynor, Martin, Kate Ho, and Robert J. Town. 2015. "The Industrial Organization of Health-Care Markets." Journal of Economic Literature, 53(2): 23584 . 
Gaynor, Martin, Rodrigo Moreno-Serra, and Carol Propper. 2013. "Death by Market Power: Reform, Competition, and Patient Outcomes in the National Health Service." American Economic Journal: Economic Policy, 5(4): 134-66.

Geweke, John, Gautam Gowrisankaran, and Robert J. Town. 2003. "Bayesian Inference for Hospital Quality in a Selection Model." Econometrica, 71(4): pp. 1215-1238.

Goeree, M. S. 2008. "Limited Information and Advertising in the US Personal Computer Industry." Econometrica, 76(5): 1017-1074.

Gowrisankaran, G., and R. J. Town. 1999. "Estimating the Quality of Care in Hospitals Using Instrumental Variables." Journal of Health Economics, 18: 747767.

Gowrisankaran, Gautam, Aviv Nevo, and Robert Town. 2015. "Mergers When Prices Are Negotiated: Evidence from the Hospital Industry." American Economic Review, 105(1): 172-203.

Gravelle, Hugh, Rita Santos, Luigi Siciliani, and Rosalind Goudie. 2012. "Hospital Quality Competition under Fixed Prices." University of York Center for Health Economics Research Paper 80.

Gutacker, Nils, Luigi Siciliani, Giuseppe Moscelli, and Hugh Gravelle. 2015. "Do Patients Choose Hospitals That Improve Their Health?" University of York Center for Health Economics Research Paper 111.

Halm, E. A., C. Lee, and M. R. Chassin. 2002. "Is Volume Related to Outcome in Health Care? A Systematic Review and Methodologic Critique of the Literature." Annals of Internal Medicine, 137(6): 511-520.

Ho, K. 2006. "The Welfare Effects of Restricted Hospital Choice in the US Medical Care Market." Journal of Applied Econometrics, 21(7): 1039-1079.

Ho, K. 2009. "Insurer-Provider Networks in the Medical Care Market." American Economic Review, 99(1): 393-430.

Honka, Elisabeth. 2014. "Quantifying Search and Switching Costs in the U.S. Auto Insurance Industry." RAND Journal of Economics. forthcoming.

Howard, David H. 2005. "Quality and Consumer Choice in Healthcare: Evidence from Kidney Transplantation." Topics in Economic Analysis and Policy, 5(1): Article 24, 1-20. http://www.bepress.com/ bejeap/topics/vol5/iss1/art24.

Hoxby, Caroline Minter. 2003. "School Choice and School Productivity: Could School Choice Be a Tide that Lifts All Boats?" In The Economics of School Choice. , ed. Caroline Minter Hoxby, 287-342. Cambridge, MA:National Bureau of Economic Research.

Kessler, D. P., and M. B. McClellan. 2000. "Is Hospital Competition Socially Wasteful?" Quarterly Journal of Economics, 155: 577-615.

Kim, J. B., P. Albuquerque, and B. J. Bronnenberg. 2010. "Online Demand under Limited Consumer Search." Marketing Science, 29(6): 1001-1023. 
Le Grand, Julian. 2003. Motivation, Agency, and Public Policy: Of Knights \& Knaves, Pawns 8 Queens. Oxford, UK:Oxford University Press.

Luft, Harold S., Deborah W. Garnick, David H. Mark, Deborah J. Peltzman, Ciaran S. Phibbs, Erik Lichtenberg, and Stephen J. McPhee. 1990. "Does Quality Influence Choice of Hospital?" JAMA: The Journal of the American Medical Association, 263(21): 2899-2906.

Mehta, N., S. Rajiv, and K. Srinivasan. 2003. "Price Uncertainty and Consumer Search: A Structural Model of Consideration Set Formation." Marketing Science, 22(1): 58-84.

Moscone, F., E. Tosetti, and G. Vittadini. 2012. "Social interaction in patients hospital choice: Evidence from Italy." Journal of the Royal Statistical Society: Series A (Statistics in Society), 175(2): 453-472.

National Hospital Discharge Survey. 2010. National Hospital Discharge Survey. Atlanta, GA:National Center for Health Statistics, Centers for Disease Control.

Nevo, Aviv. 2003. "New Products, Quality Changes, and Welfare Measures Computed from Estimated Demand Systems." Review of Economics and Statistics, 85(2): 266-275.

Propper, Carol. 2012. "Competition, Incentives and the English NHS." Health Economics, 21(1).

Propper, C., M. Sutton, C. Whitnall, and F. Windmeijer. 2008. "Did Targets and Terror Reduce Waiting Times in England for Hospital Care?" The BE Journal of Economic Analysis \&5 Policy, 8(2): 5.

Propper, C., M. Sutton, C. Whitnall, and F. Windmeijer. 2010. "Incentives and Targets in Hospital Care: Evidence from a Natural Experiment." Journal of Public Economics, 94(3-4): 318-335.

Roberts, J. H., and J. M. Lattin. 1991. "Development and Testing of a Model of Consideration Set Composition." Journal of Marketing Research, 28(4): 429440.

Santos, Rita, Hugh Gravelle, and Carol Propper. 2015. "Does quality affect patients' choice of Doctor? Evidence from England." The Economic Journal. forthcoming.

Seiler, S. 2013. "The Impact of Search Costs on Consumer Behavior: A Dynamic Approach." Quantitative Marketing and Economics, 11(2): 155-203.

Silber, J. H., P. R. Rosenbaum, R. N. Brachet, T. J.and Ross, L. J. Bressler, O. Even-Shoshan, S. A. Lorch, and K. G. Volpp. 2010. "The Hospital Compare Mortality Model and the Volume-Outcome Relationship." Health Services Research, 45: 1148-1167.

Sivey, P. 2008. "The Effect of Hospital Quality on Choice of Hospital for Elective Heart Operations in England." Unpublished Manuscript, University of Melbourne. 
Small, K. A., and H. S. Rosen. 1981. "Applied Welfare Economics with Discrete Choice Models." Econometrica, 49(1): 105-130.

Tay, A. 2003. "Assessing Competition in Hospital Care Markets: the Importance of Accounting for Quality Differentiation." RAND Journal of Economics, 34(4): 786-814.

Train, K. E. 2003. Discrete Choice Methods with Simulation. New York:Cambridge University Press.

van Domburg, R. T., A. P. Kappetein, and A. J. J. C. Bogers. 2009. "The Clinical Outcome After Coronary Bypass Surgery: A 30-year Follow-up Study." European Heart Journal, 30: 453-458.

Varkevisser, Marco, Stéphanie A. van der Geest, and Frederik T. Schut. 2012. "Do patients choose hospitals with high quality ratings? Empirical evidence from the market for angioplasty in the Netherlands." Journal of Health Economics, 31(2): $371-378$. 
Table 1 -Descriptive Statistics - Hospital Characteristics

\begin{tabular}{|c|c|c|c|c|c|c|}
\hline & & $\begin{array}{c}\text { Total } \\
\text { Admissions }\end{array}$ & & $\begin{array}{l}\text { Waiting Times } \\
\text { (Days) }\end{array}$ & & $\begin{array}{c}\text { Mortality } \\
\text { Rate }\end{array}$ \\
\hline & Mean & Standard Deviation & Mean & Standard Deviation & Mean & Standard Deviation \\
\hline 2003 & 497.7 & 178.4 & 109.1 & 32.1 & 1.32 & 0.62 \\
\hline 2004 & 486.8 & 194.9 & 100.5 & 20.7 & 1.42 & 0.69 \\
\hline 2005 & 423.8 & 153.9 & 67.8 & 15.2 & 1.25 & 0.52 \\
\hline 2006 & 385.5 & 160.3 & 65.6 & 17.3 & 1.52 & 0.81 \\
\hline 2007 & 419.9 & 146.7 & 64.9 & 21.4 & 0.99 & 1.02 \\
\hline
\end{tabular}

Note: The table reports descriptive statistics for all hospitals performing CABGs from 2003 to 2007. To compute the columns in the table, the hospital-year level values of the variables are calculated. The means and standard deviations are based purely on between-hospital variation within each year.

Source: Hospital Episode Statistics (HES), UK Department of Health. 


\begin{tabular}{lccccc}
\hline & & & & & \\
& Mean & Median & $\begin{array}{c}\text { Standard } \\
\text { Deviation }\end{array}$ & $\begin{array}{c}\text { 10th } \\
\text { Percentile }\end{array}$ & $\begin{array}{c}90 \text { th } \\
\text { Percentile }\end{array}$ \\
\hline Age & 65.76 & 66 & 55.04 & 53 & 76 \\
Fraction Male & 0.81 & & & & \\
Index of Multiple Deprivation & 0.14 & 0.11 & 0.12 & 0.04 & 0.31 \\
Comorbidity Count & 5.42 & 5 & 2.81 & 2 & 9 \\
Charlson Index & 0.55 & 0 & 0.71 & 0 & 2 \\
Distance Pre-reform & 34.93 & 22.34 & 44.97 & 4.77 & 71.40 \\
Distance Post-reform & 32.24 & 22.91 & 32.94 & 4.93 & 70.58 \\
& & & & & \\
\hline
\end{tabular}

Source: Hospital Episode Statistics (HES), UK Department of Health. 
Table 3-Reduced-Form Evidence: Regressions using Aggregate Market-Shares

\begin{tabular}{lcccc}
\hline & $(1)$ & $(2)$ & $(3)$ & $(4)$ \\
Dependent Variable & $\begin{array}{c}\text { Elective CABGs } \\
\text { Market-share }\end{array}$ & $\begin{array}{c}\text { Emergency CABG } \\
\text { Market-share }\end{array}$ \\
& Pre-reform & Post-reform & Pre-reform & Post-reform \\
Time Period & & & & \\
\hline & -0.001 & -0.177 & 0.031 & -0.046 \\
$\begin{array}{l}\text { Mortality Rate } \\
\text { Coefficient }\end{array}$ & $(0.047)$ & $(0.034)$ & $(0.066)$ & $(0.053)$ \\
& & & & \\
& & & & Yes \\
Hospital Fixed Effects & Yes & Yes & 142 & 143 \\
$\begin{array}{l}\text { Observations } \\
\text { Hospitals }\end{array}$ & 142 & 143 & 29 & 29 \\
Quarters & 29 & 29 & 5 & 5 \\
\hline
\end{tabular}

Note: Standard errors are reported in parentheses. 
Table 4-Reduced-Form Evidence: Changes in the Expected Mortality Rate

\begin{tabular}{lccc}
\hline Sample & $\begin{array}{c}\text { Mean Mortality } \\
\text { Rate Pre-reform }\end{array}$ & $\begin{array}{c}\text { Mean Mortality } \\
\text { Rate Post-reform }\end{array}$ & $\begin{array}{c}\text { Difference } \\
\text { in Means }\end{array}$ \\
\hline All Patients & 1.330 & 0.935 & -0.395 \\
& $(0.007)$ & $(0.009)$ & $(0.011)$ \\
Patients Visiting & 1.276 & 1.027 & -0.249 \\
the Nearest Hospital & $(0.008)$ & $(0.011)$ & $(0.013)$ \\
Patients Not Visiting & 1.445 & 0.735 & -0.711 \\
the Nearest Hospital & $(0.015)$ & $(0.015)$ & $(0.021)$ \\
\hline
\end{tabular}

Note: Standard errors are reported in parentheses. 


\begin{tabular}{|c|c|c|c|}
\hline & & Coefficient & $\begin{array}{l}\text { Standard } \\
\text { Error }\end{array}$ \\
\hline \multirow{8}{*}{$\begin{array}{l}\text { Patient } \\
\text { Preferences }\end{array}$} & Distance & -6.983 & 0.211 \\
\hline & Closest Hospital Dummy & 1.341 & 0.052 \\
\hline & Mortality Rate & -7.883 & 2.229 \\
\hline & Mortality Rate ${ }^{*}$ High Severity & -5.419 & 2.467 \\
\hline & Mortality Rate ${ }^{*}$ High Income & 3.832 & 2.320 \\
\hline & Waiting Times & -1.528 & 1.887 \\
\hline & Waiting Times * High Severity & -1.584 & 1.140 \\
\hline & Waiting Times $*$ High Income & 6.262 & 1.196 \\
\hline \multirow{3}{*}{$\begin{array}{l}\text { Physician } \\
\text { Preferences }\end{array}$} & Distance & -4.985 & 0.207 \\
\hline & Closest Hospital Dummy & 1.734 & 0.110 \\
\hline & Within-PCT Dummy & 1.309 & 0.308 \\
\hline \multirow{3}{*}{$\begin{array}{l}\text { Choice } \\
\text { Constraint } \\
\text { Parameters }\end{array}$} & Constant & 0.000 & 0.119 \\
\hline & High Severity & 1.011 & 0.178 \\
\hline & High Income & 0.000 & 0.113 \\
\hline
\end{tabular}




\section{Panel A}

$\begin{array}{lccc}\text { Patient-level } & \text { Consideration } & \text { Sensitivity } & \text { Sensitivity } \\ \text { Sensitivity } & \text { Set Size } & \text { to Quality } & \text { to Quality } \\ \text { (by characteristics) } & \text { (Pre-reform) } & \text { Pre-reform } & \text { Post-reform }\end{array}$

$\begin{array}{lccc}\text { Low Severity, Low Income } & 1 & 0 & -1.209 \\ & (0.037) & (0.041) & (0.317) \\ \text { Low Severity, High Income } & 1 & 0 & -0.637 \\ & (0.056) & (0.035) & (0.272) \\ \text { High Severity, Low Income } & 1.611 & -0.486 & -1.972 \\ & (0.110) & (0.090) & (0.354) \\ \text { High Severity, High Income } & 1.611 & -0.354 & -1.438 \\ & (0.108) & (0.083) & (0.323)\end{array}$

\section{Panel B \\ Hospital-level Sensitivity}

Mean

$\begin{array}{cc}\text { Standard } & 25 \text { th } \\ \text { Deviation } & \text { Percentile }\end{array}$

Median

75 th

Deviation Percentile Percentile

\begin{tabular}{lccccc}
\hline Pre-reform & -0.82 & 0.65 & -1.33 & -0.56 & -0.30 \\
& $(0.17)$ & & & & \\
Post-reform & -4.46 & 2.57 & -6.53 & -3.69 & -2.38 \\
& $(0.70)$ & & & \\
Change & -3.50 & 1.97 & -4.37 & -3.09 & -2.04 \\
& $(0.60)$ & & & \\
\hline
\end{tabular}

Note: The top panel reports the pre-reform consideration set size and the responsiveness of demand at the patient-level with respect to the mortality rate. The values reported in the second and third column represent the average percentage change in the choice probability when a hospital increases the mortality rate by one standard deviation. The bottom panel reports the distribution of percentage changes (across all hospitals) in market share when a hospital increases the mortality rate by one standard deviation. Bootstrapped standard errors are reported in parentheses. 


\section{Panel A}

Impact on Patient Survival
Change in Survivals when

Post-reform Choices are Constrained

Post-Reform Admissions

14,968

(5 quarters)
Deaths

Mortality Rate

Recomputed Mortality Rate

Under Constraints
140

0.94

0.96

\section{Panel B}

Percentage Change in

Market Shares

Due to the Reform

\begin{tabular}{ccccc} 
Mean & $\begin{array}{c}\text { Standard } \\
\text { Deviation }\end{array}$ & $\begin{array}{c}25 \text { th } \\
\text { Percentile }\end{array}$ & Median & $\begin{array}{c}75 \text { th } \\
\text { Percentile }\end{array}$ \\
-3.77 & 22.83 & -15.92 & 2.14 & 13.49 \\
\hline
\end{tabular}

\section{Panel C}

Supply-side Response
Dependent Variable

Change in the Elasticity

of Demand with Respect

to the Mortality Rate
Change in Mortality Rate

$-0.328$

Observations

Note: Panel A reports the change in the number of survivals when constraints are removed. Panel B shows the changes in market-shares across hospitals for the counterfactual scenario of an earlier removal of constraints. This entails a zero-sum game of market-share reshuffling between hospitals. The distribution of changes across hospitals is reported. Panel $\mathrm{C}$ reports results from an OLS regression of a change in mortality on the change in the elasticity of demand (derived from the demand model). 


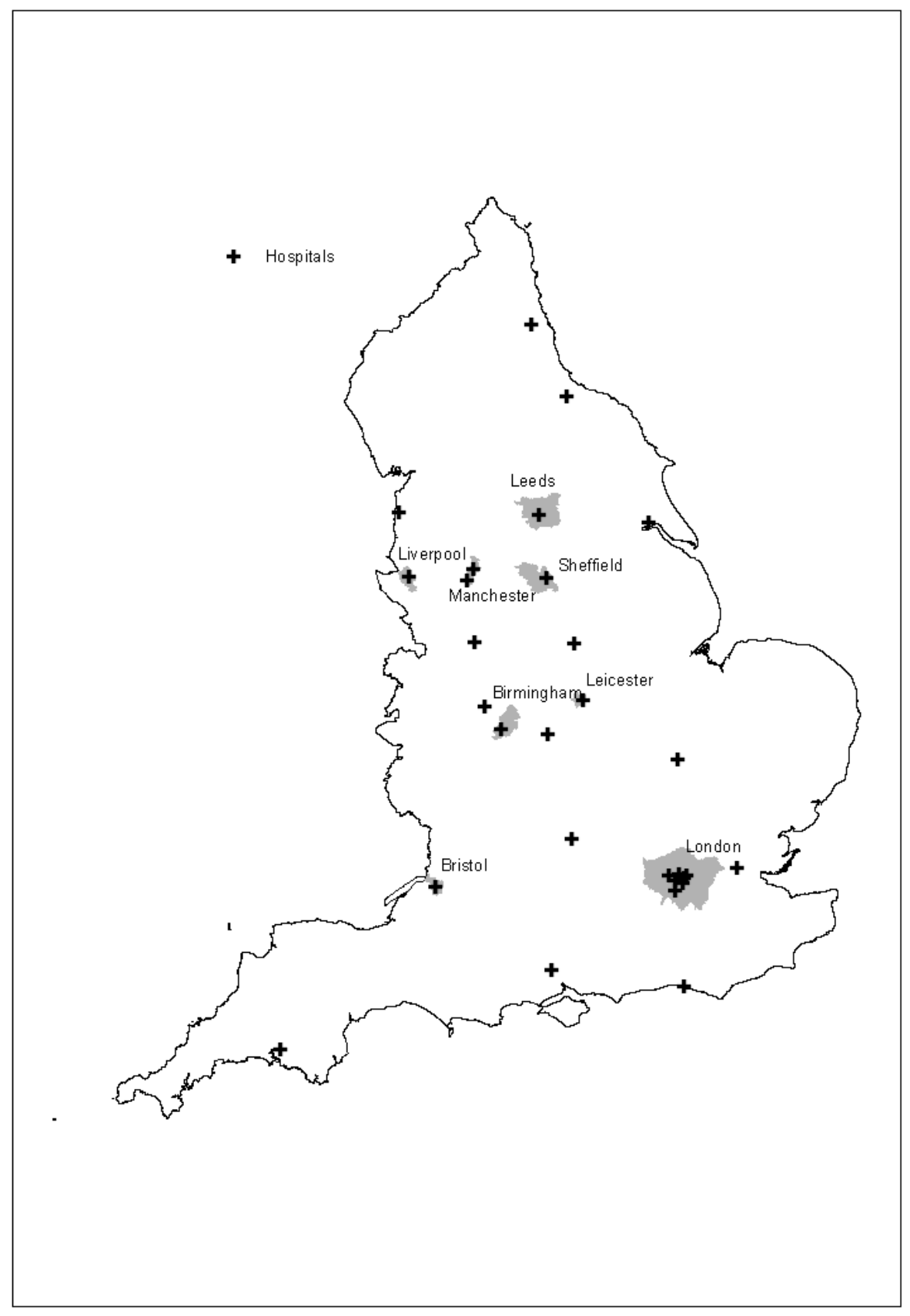

